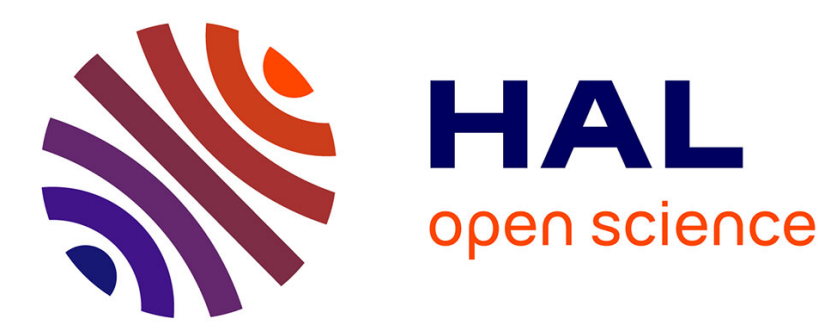

\title{
La Tour des Archives et le fort des Tourelles de Vernon (Eure). Deux édifices royaux exceptionnels édifiés vers 1200
}

\author{
Jean Mesqui
}

\section{- To cite this version:}

Jean Mesqui. La Tour des Archives et le fort des Tourelles de Vernon (Eure). Deux édifices royaux exceptionnels édifiés vers 1200. Bulletin Monumental, 2011, 169 (4), pp.291-316. 10.3406/bulmo.2011.8004 . halshs-01372868

\section{HAL Id: halshs-01372868 \\ https://shs.hal.science/halshs-01372868}

Submitted on 27 Sep 2016

HAL is a multi-disciplinary open access archive for the deposit and dissemination of scientific research documents, whether they are published or not. The documents may come from teaching and research institutions in France or abroad, or from public or private research centers.
L'archive ouverte pluridisciplinaire HAL, est destinée au dépôt et à la diffusion de documents scientifiques de niveau recherche, publiés ou non, émanant des établissements d'enseignement et de recherche français ou étrangers, des laboratoires publics ou privés. 


\title{
LA TOUR DES ARCHIVES ET LE FORT DES TOURELLES DE VERNON (EURE)
}

\section{DEUX ÉDIFICES ROYAUX EXCEPTIONNELS ÉDIFIÉS VERS 1200}

\author{
Jean MESQUI
}

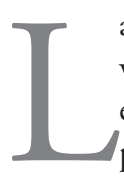

a petite ville de Vernon, première ville normande que l'on rencontre en descendant la Seine après avoir passé Mantes et la Roche-Guyon, conserve de ses fortifications médiévales deux monuments assez souvent cités et qui n'ont pourtant jamais été étudiés réellement : le château royal, implanté en rive gauche de Seine, dont l'élément le plus emblématique est l'ancienne tour maîtresse, dite tour des Archives, attribuée en général à Philippe Auguste, et le fort des Tourelles, situé à Vernonnet en rive droite de Seine, demeuré dans une sorte de purgatoire, tant ses modifications externes apportées à l'époque classique et moderne ont pu dérouter les spécialistes ${ }^{1}$.

Ces édifices méritent une attention particulière, en raison de leurs caractéristiques architecturales et de leur décor, remarquables, qui en font des témoins tout à fait privilégiés de l'architecture royale de l'extrême fin du XII ${ }^{\mathrm{e}}$ siècle.

\section{LE CONTEXTE HISTORIQUE ET TOPOGRAPHIQUE}

\section{Rappel historique}

Si la ville de Vernon est sans doute d'origine purement médiévale ${ }^{2}$, le site de traversée de la Seine a vraisemblablement existé d'antiquité. En rive droite, face à l'agglomération moderne, le plateau porte les restes d'un oppidum qui fut le plus étendu en superficie de tous les oppida des Veliocasses; des fouilles récentes ont permis de dégager des parties importantes de son enceinte - tout particulièrement les restes de sa porte monumentale ; elles ont montré que son utilisation s'est sans doute maintenue jusqu'au I ${ }^{\text {er }}$ siècle de notre ère. À son extrémité fut implantée une chapelle dédiée à saint Michel, devenue prieuré au Moyen Âge ${ }^{3}$.

Ce n'est cependant qu'à la fin du $\mathrm{X}^{\mathrm{e}}$ siècle que Vernon apparaît dans l'histoire ${ }^{4}$; le noyau de population s'établit en rive gauche de Seine, contrôlant le chemin de Mantes à Rouen longeant la Seine et la traversée du fleuve ; la région était particulièrement prospère du fait de l'existence d'un vignoble réputé, le vignoble de Longueville, qui se développait sur les coteaux occidentaux de la vallée, de Vernon à Gaillon ${ }^{5}$.

Le castrum de Vernon est mentionné dès avant les années 1040 ; le roi-duc Henri ${ }^{\text {er }}$ y construisit une tour maîtresse en 1123, lors de la grande campagne de fortification qu'il mena en Normandie à cette époque ${ }^{6}$. Le site de traversée était doté d'un pont avant le milieu du $\mathrm{XII}^{\mathrm{e}}$ siècle, si l'on en croit Robert de Torigni qui relate la traversée de la Seine en 1144 par l'armée de Geoffroy d'Anjou, puis cite le pont en évoquant la traversée par l'armée du duc Henri Plantagenêt, futur Henri II, en $1152^{7}$. Dès cette époque, le bourg castral était devenu une ville à part entière : une collégiale dédiée à Notre-Dame y avait été fondée dès le troisième quart du
$\mathrm{XI}^{\mathrm{e}}$ siècle et une seconde église, dédiée à sainte Geneviève, y existait peut-être dès le XII ${ }^{\mathrm{e}}$ siècle.

Vernon était donc un site majeur, à quelques kilomètres de la frontière avec l'Ile-de-France ; château, ville et pont furent en conséquence un enjeu permanent dans le conflit franco-anglo-normand dans la seconde moitié du XII ${ }^{\mathrm{e}}$ siècle. Le bourg situé à l'extérieur des murs fut incendié par Louis VII, en avril 1153, en représailles aux exactions de Richard I de Vernon ; la même année, en juillet, le roi, aidé par le comte de Flandre Thierry d'Alsace et son armée, assiégea le castrum. Selon Robert de Torigny, le castrum aurait résisté pendant quinze jours à tous les assauts et à diverses machines de guerre ; le roi, inquiet du départ annoncé de Thierry d'Alsace, aurait alors négocié avec Richard I de Vernon un compromis. L'oriflamme royal devait être hissé à la tour du château et celle-ci confiée à la garde de Goël, fils de Baudry de Baudemont, déjà vassal du roi en raison de la remise du Vexin normand par le duc Henri en 1150, ainsi que de Richard de Vernon. Quoi qu'ait pensé et écrit le chroniqueur à propos de cet épisode, le castrum demeura sous contrôle de Louis VII jusqu'en août 1154, date à laquelle, à l'occasion de la trêve signée entre les deux princes, il réintégra l'orbite ducale ; on notera qu'il était qualifié à cette époque de " château extrêmement fort " (firmissimum castrum) ${ }^{8}$.

Quarante ans plus tard, Philippe Auguste, déjà maître de Gisors par traîtrise en 1193, 


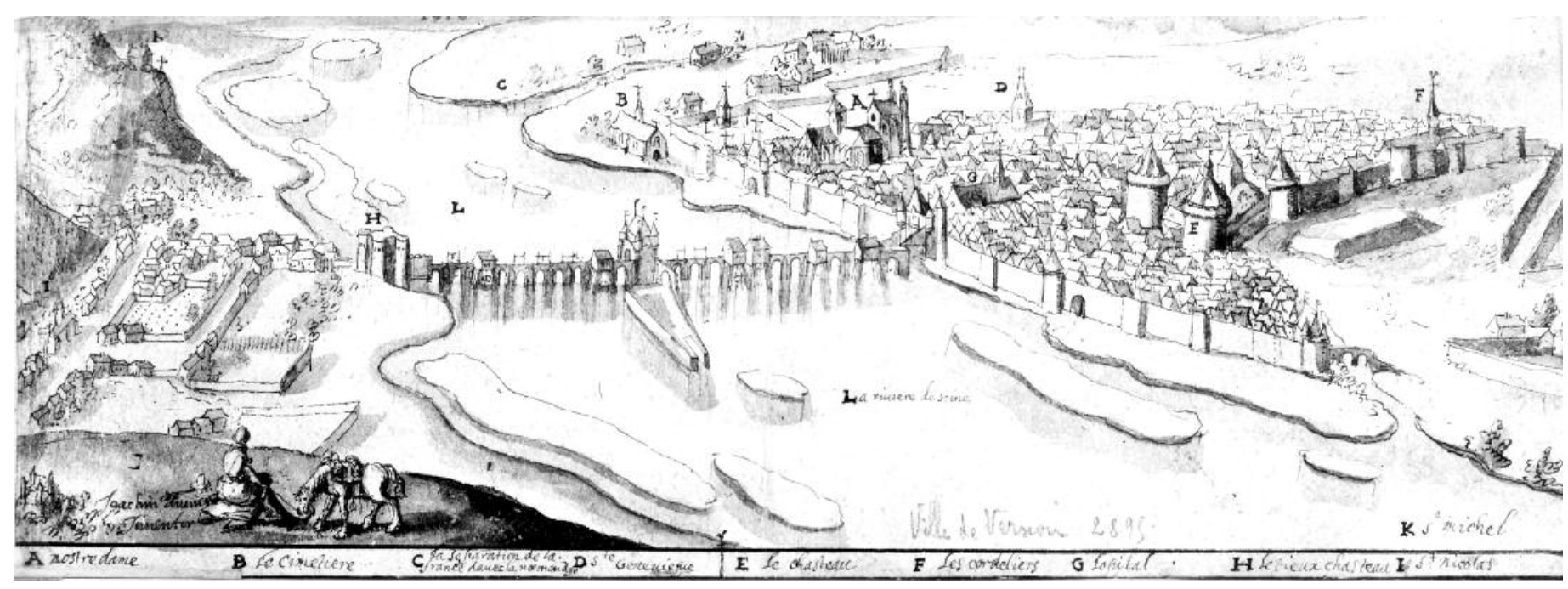

Fig. 1 - Vue de la ville de Vernon, par Joachim Duviert vers 1610 (B.n.F., Vx23 rés.). On reconnaît de gauche à droite le fort des Tourelles, la section nord du pont, la porte du Pont sur l'île du Talus, la section sud du pont, la porte du Pont de l'enceinte urbaine, et à droite le château royal. La légende donne : A - Notre-Dame . B - Le cimetière. C - La séparation de la France d'avec la Normandie. D - Ste-Geneviève. E - Le chasteau. F - Les Cordeliers. G - L'ôpital. H - Le vieux chasteau. I - St-Nicolas. K - St-Michel.

s'empara de la vallée de l'Eure en 1194 . À la fin de 1195, le rapport de force était tel autour de Vernon que le roi de France fut en situation d'imposer un abandon par le seigneur titulaire, Richard II de Vernon ; en échange, Philippe Auguste lui donnait le château de Montmélian situé au nord de Paris (commune de Saint-Witz, Val-d'Oise) et les droits afférents, ce qui était autrement moins valorisant mais dut paraittre un compromis acceptable par Richard II qui se voyait, par ailleurs, confirmer la seigneurie de Néhou en Cotentin par Richard I ${ }^{\text {er }}$ d'Angleterre ${ }^{9}$.

Dès lors, Vernon demeura châtellenie royale, particulièrement fréquentée par Philippe Auguste, puis par tous les rois ou les princesses apanagistes ${ }^{10}$. À partir du $\mathrm{XVI}^{\mathrm{e}}$ siècle, la châtellenie fut systématiquement aliénée au profit de princes de la maison royale ou de grands dignitaires ${ }^{11}$. C'est sous les deux derniers d'entre eux, le maréchal de Belle-Isle et le duc de Penthièvre, que le château commença d'être démantelé (1752), puis l'enceinte de la ville (1779). Cependant la disparition de celle-ci fut plus rapide que celle de l'enceinte castrale dont l'arasement ne se produisit que dans les années 1950 , lors de la Reconstruction.

\section{Les composantes de l'agglomération fortifiée}

Le développement du castrum, puis de la ville fortifiée, fut évidemment intimement lié au croisement entre la traversée de la Seine de direction sud-ouest-nord-est faisant partie d'un itinéraire BeauvaisÉvreux et la route de Paris à Rouen en rive gauche qui lui était perpendiculaire. Dans sa forme définitive, qui prévalut à partir du XIII e siècle, la ville était formée de trois composantes imbriquées : l'enceinte urbaine enveloppant les deux bourgs primitifs, formant un grand triangle rectangle appuyé sur la Seine, interceptant les deux rues majeures ; la deuxième enceinte ovalaire, englobant les développements urbains intervenus au XII siècle, et, à la charnière entre les deux enceintes, le château royal qui avait une courtine commune avec la première enceinte (fig. 3). Nous reviendrons dans un autre article sur la genèse, semble-t-il complexe, de cet urbanisme et sur l'emplacement du castrum primitif ${ }^{12}$.

La fortification de la ville fut ainsi fixée dans son extension maximale au cours du XIII siècle ; elle ne varia plus après cette date, seuls des aménagements ponctuels y intervenant au cours du XVI ${ }^{\mathrm{e}}$ siècle ${ }^{13}$.
Aux fortifications de la ville stricto sensu s'ajoutaient évidemment celles du pont de Vernon sur la Seine. Celui-ci débouchait au sud sur une des portes de la ville - la porte du Pont ; au nord, sur la rive droite de la Seine, il était placé sous la surveillance d'une fortification particulière, le fort des Tourelles, appelé au Moyen Âge tour ou château de Vernonnet (fig. 1, H) ${ }^{14}$.

En plus de cette tête de pont fortifiée, fut construite à une époque indéterminée, une tour-porte située sur l'île du Talus au milieu de la Seine. Cette île abritait primitivement l'Hôtel-Dieu de Vernon avant qu'il ne soit transféré, après 1256 , sur le site de l'ancien castrum. La tour-porte est mentionnée à notre connaissance pour la première fois en 1426 et elle est qualifiée à cette époque de neuve, soit qu'elle ait été construite a nibilo à cette date, soit encore reconstruite ${ }^{15}$. Elle est encore figurée dans les dessins des années 1650-1660 (fig. 4), mais elle était en ruines dès 1718 et disparut avant $1780{ }^{16}$.

\section{LE CHÂTEAU ROYAL}

Le château royal est connu par plusieurs anciens plans et descriptions ; il a fait l'objet d'une notice assez complète par 
Dominique Pitte, après les fouilles de sauvetage menées en 1986-1989 ${ }^{17}$. On se contentera donc de rappeler ses caractéristiques principales avant de décrire les éléments encore conservés. L'enceinte formait une sorte de fer à cheval raccordé à ses deux extrémités à la première enceinte de la ville : au nord, la jonction s'effectuait par l'intermédiaire de la Grosse tour, dite aujourd'hui tour des Archives, alors qu'au sud-est se trouvait une tourelle d'angle, au-delà de laquelle l'enceinte allait rejoindre la porte de la première enceinte disparue dès le XVIII siècle (fig. 5).

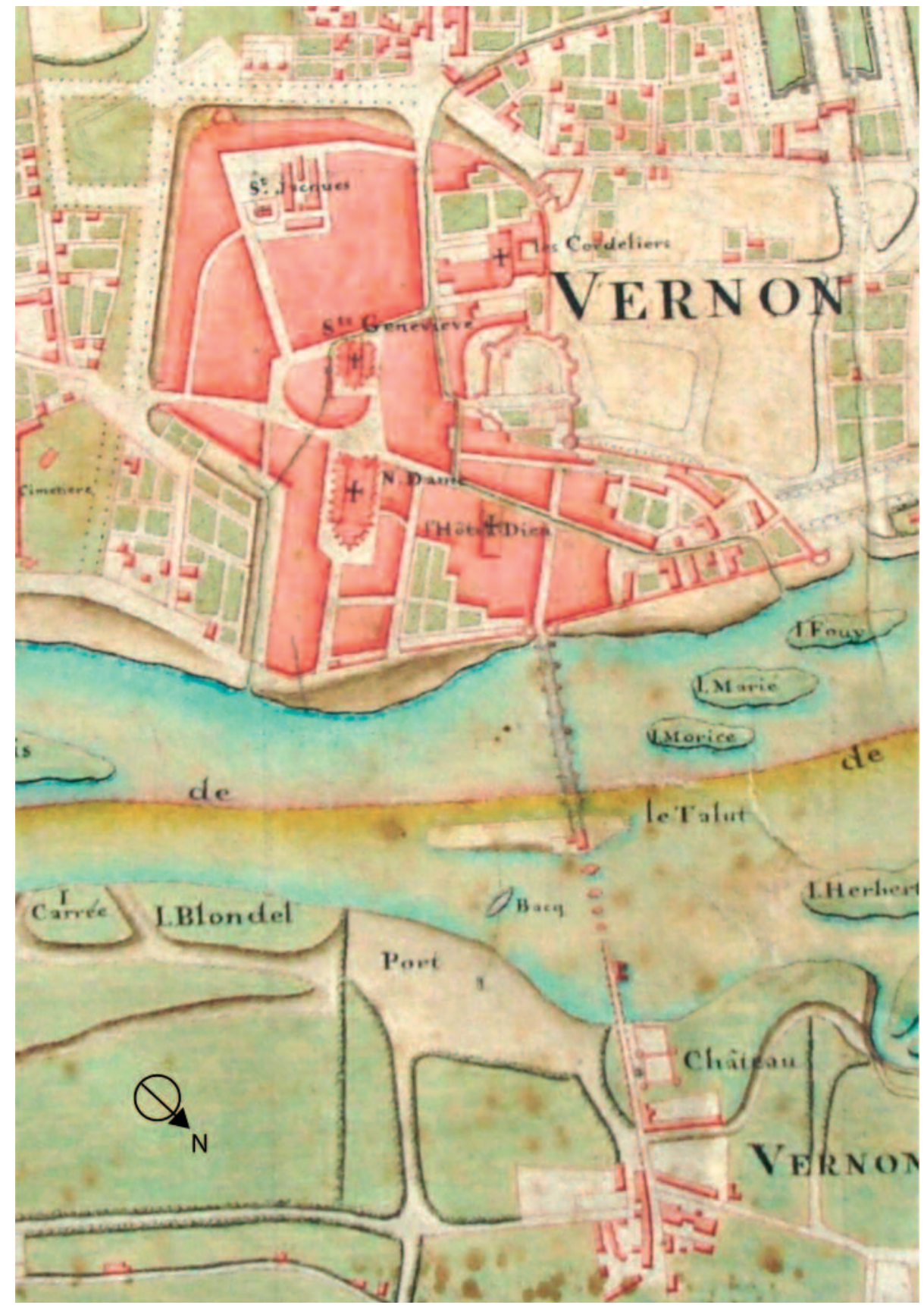

Fig. 2 - Plan de Vernon en 1752 (Arch. dép. Eure). Le contour de l'enceinte urbaine est encore parfaitement reconnaissable, ainsi que celle du château. Le pont apparaît avec ses deux sections sur les deux bras de Seine, séparées par l'île du Talus : au sud, il est encore en état de fonctionnement, alors qu'au nord, la seconde section est largement ruinée et remplacée par un bac. Au bout de la deuxième section se trouve le fort des Tourelles, intitulé "Château ».
L'enceinte était flanquée sur son ovale occidental par cinq tourelles-contreforts semi-circulaires, entre lesquelles s'intercalaient irrégulièrement de grandes tours creuses ; selon le plan de 1779, il existait sept de ces grandes tours, en y incluant la tourelle d'angle mentionnée ci-dessus et les deux tours de la porte sud, mais on sait par le plan de 1593 qu'il existait, en outre, une tour-porte supplémentaire vers le nord, donnant sur le boulevard rectangulaire septentrional (fig. 5, $\mathrm{n}^{\circ}$ 5) ${ }^{18}$. Cette porte fut probablement supprimée lors de l'aménagement des Grandes écuries en 1752.

\section{L'enceinte en fer à cheval et la tourelle semi-circulaire pleine}

De l'arrondi formant autrefois le dessus du fer à cheval dessiné par l'enceinte ne subsiste qu'un moignon de courtine d'une dizaine de mètres de longueur, encore flanqué par une tourelle semi-circulaire pleine. Lors des fouilles préventives, les archéologues avaient exhumé un fragment de courtine adjacent, long d'une vingtaine de mètres, conservé depuis le fond du fossé jusqu'au niveau du sol ${ }^{19}$. Il s'agissait d'un mur rectiligne pourvu d'un léger fruit, ne présentant l'appareil médiéval primitif qu'à partir de $-2 \mathrm{~m}$ sous le sol environnant; le parement est construit dans un appareil assisé de petits mœllons équarris. Audessus se superposent un niveau faisant alterner des assises irrégulières, et un parement supérieur très irrégulier moderne. Le dégagement des fossés n'a pas livré de couches archéologiques, de telle sorte que la datation de la courtine ne repose que sur des céramiques, trouvées à l'intérieur de l'enceinte, qui remonteraient à la seconde moitié du XII ${ }^{\mathrm{e}}$ siècle au plus tôt ${ }^{20}$.

Le fragment de courtine flanqué par une tourelle semi-circulaire qui subsiste en élévation en fait partie ; il a conservé une élévation d'une dizaine de mètres mais les parements ont été altérés et remaniés à de nombreuses reprises jusqu'à l'époque moderne, au point qu'il est vain de tenter de les analyser précisément. On décèle d'ailleurs la présence au sud de la tour d'une poterne, percée manifestement à la 


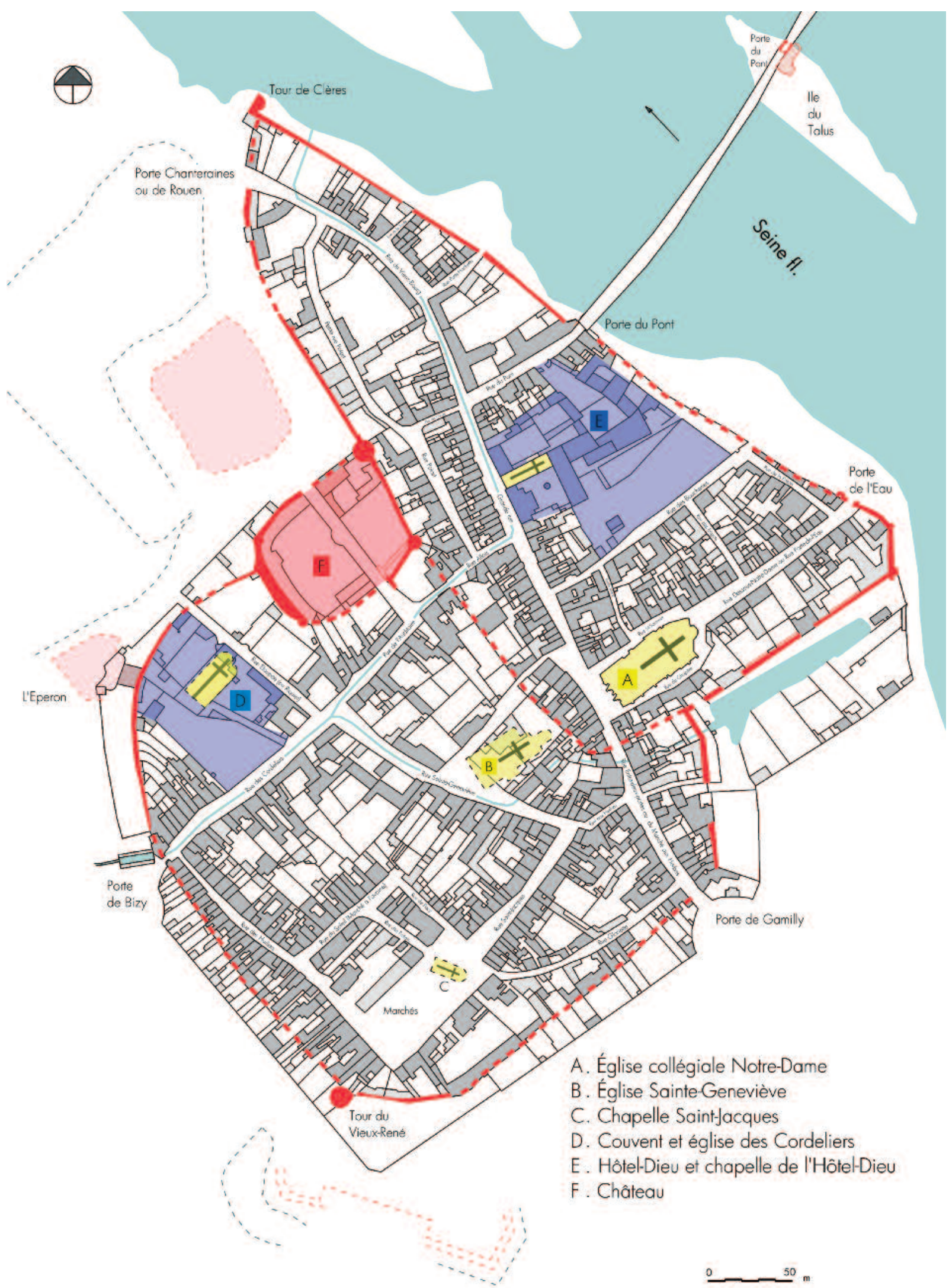

Fig. 3 - Plan synoptique de la ville de Vernon d'après le cadastre de 1829 et les plans anciens (voir note 17). 


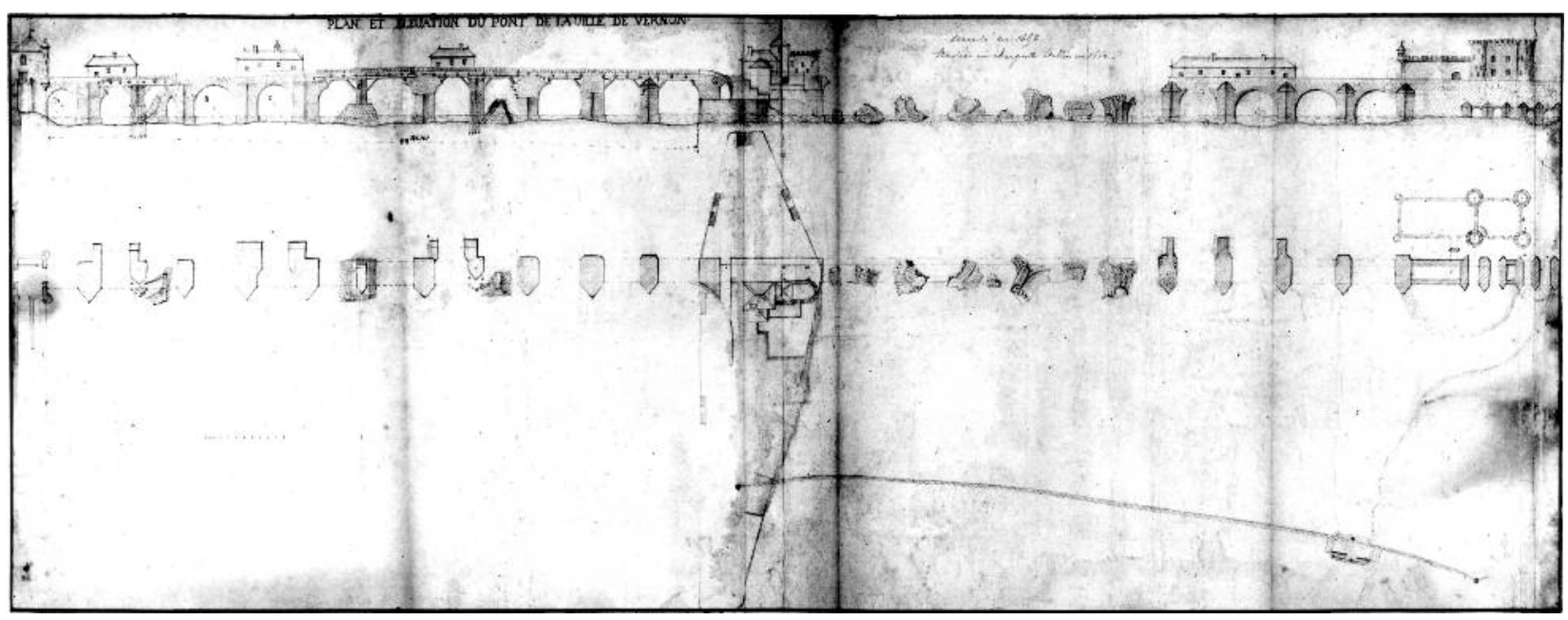

Fig. 4 - Vernon, plan et élévation du pont après les crues catastrophiques de 1658 et après la construction de travées en charpente sur le bras sud en 1662 (Arch. nat., F14 10196-13-04).
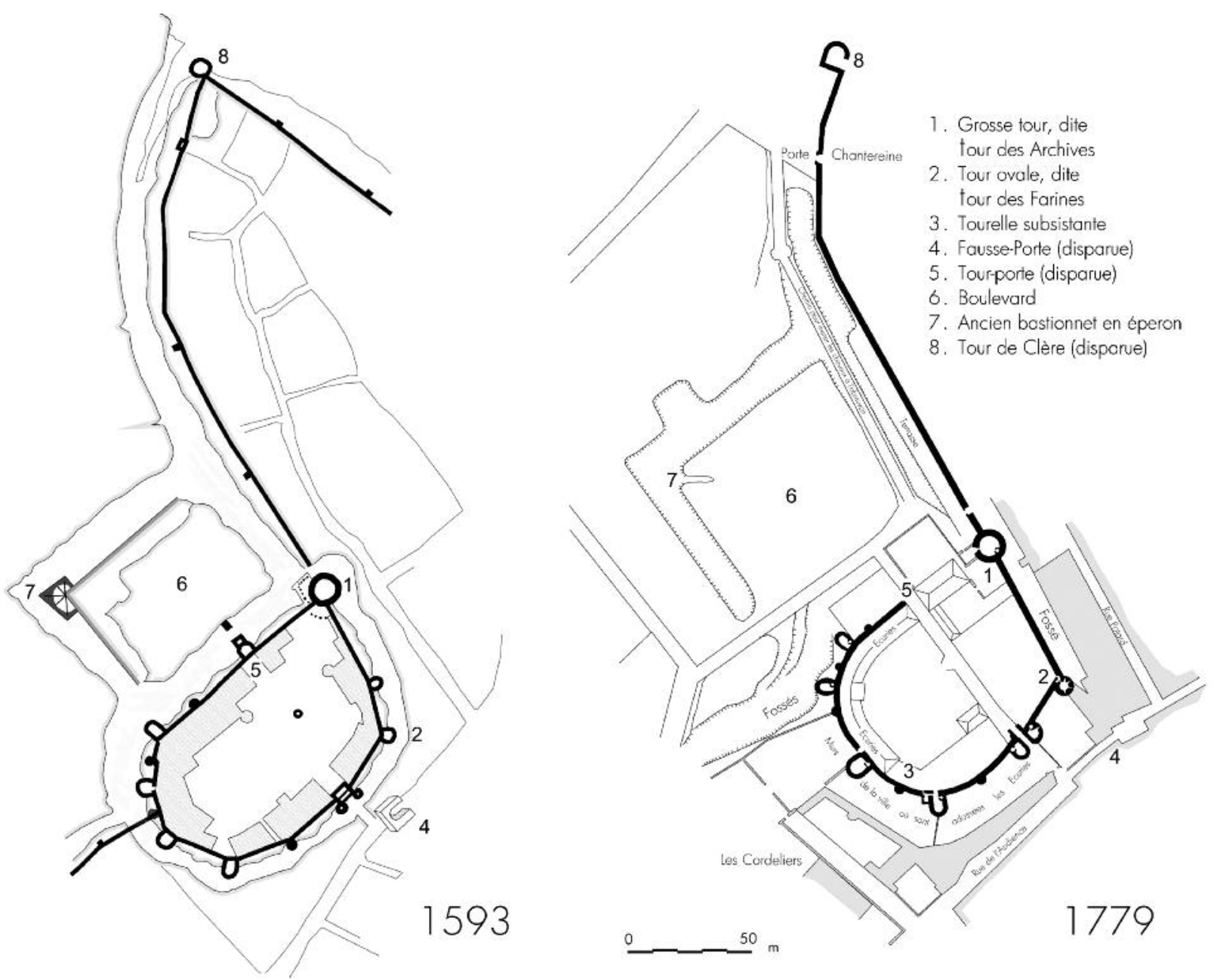

Fig. 5 - À gauche : «Plan geometrial de la ville de Vernon sur Seyne avec l'elevation des bastimentz publiques " (1593) (d'après l'original conservé à la B.n.F.). À droite : « Plan d'une partie de la ville de Vernon, avec l'emplacement où sont construites les écuries pour les chevaux des Gardes du Roy " (1779) (d'après l'original conservé au musée de Vernon). Le plan de 1593 représente le château encore entièrement enclos, avec son boulevard et sa tour bastionnée. Le plan de 1779 a le grand avantage de figurer l'enceinte du château dans son état antérieur à la destruction des tours sud-ouest, c'est-à-dire vers 1752, alors qu'était prise la décision de construire les grandes Écuries et de percer la nouvelle rue au milieu du château. 


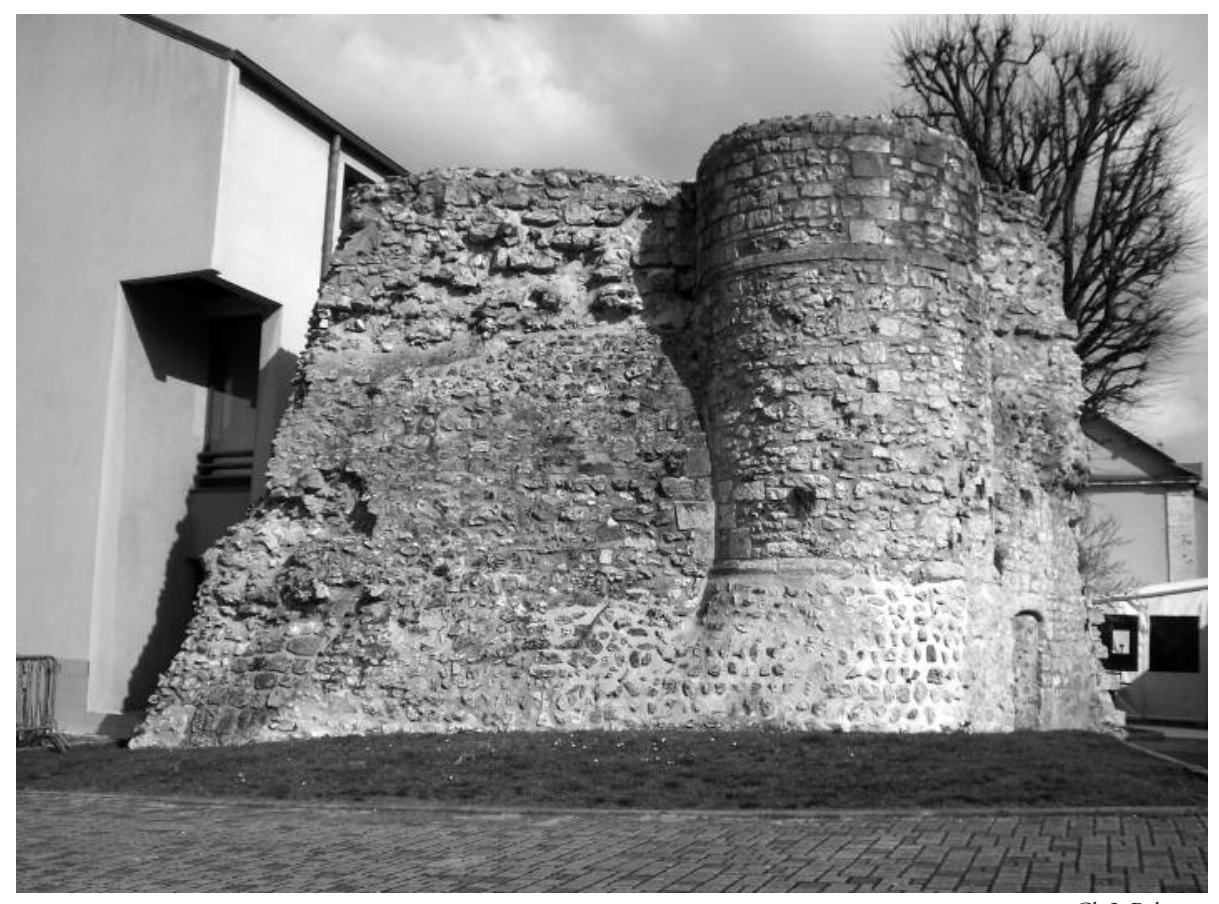

Fig. 6 - Vernon, vue de la tourelle semi-circulaire pleine, prise depuis le sud-ouest.

Cl. J. Baboux.

fin du Moyen Âge pour faciliter la circulation entre le château et son fossé, qui fut sans doute murée au XVIII siècle.

La tourelle semi-circulaire pleine, d'un diamètre d'environ $4 \mathrm{~m}$, était marquée par deux assises en glacis l'amincissant à mesure de sa hauteur ; la première se trouvait juste au-dessus du talus de base très
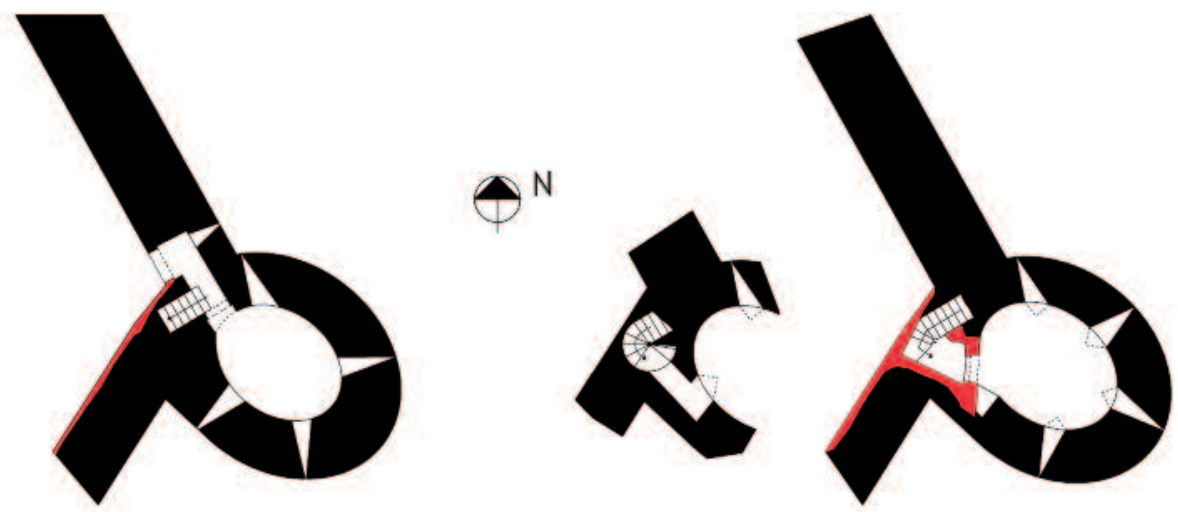

remanié qui la garnissait, la seconde à six mètres. Au-dessus de cette seconde assise de retrait, le parement de la tour, jusque là très irrégulier, se transforme en un appareil réglé de mœellons équarris.

On peut supposer que les autres tourelles pleines de l'enceinte avaient la même facture ; mais celle qui est conservée

État
restitué

État

actuel

Niveau 2 ne donne aucun renseignement sur la date de construction possible. Dominique Pitte avait proposé de les attribuer à la seconde moitié du XII ${ }^{\mathrm{e}}$ siècle, datation que nous avions reprise en la justifiant par la similitude de parti avec les tourelles semi-circulaires attribuées à Henri II dans les enceintes de Poitiers et de Loches, aux tours maîtresses de Niort, etc. ; cette proposition est désormais couramment admise ${ }^{21}$. Pour autant, elle doit être utilisée avec une grande prudence : le manque total d'éléments architecturaux - hormis les deux assises en ressauts à glacis qui marquent son élévation - pourrait justifier toute datation comprise entre le début du $\mathrm{XII}^{\mathrm{e}}$ siècle et la fin du XIV ${ }^{e}$ siècle.

Aucun indice d'aucune sorte n'existe plus sur les tours flanquant autrefois cette enceinte en fer à cheval. Le plan de 1779 représente des tours en U collées aux courtines, confirmant en cela le plan moins précis de 1593 ; la salle basse de chacune d'elles était desservie par un escalier en vis ménagé dans l'angle intérieur entre tour et courtine. Ce plan ne donne cependant pas le moindre élément d'information sur les percements éventuels des salles basses, peut-être bouchés à l'époque où on le levait.

Malgré cette absence d'éléments de datation, on peut suggérer - sous toute réserve - une datation tardive pour ces tours collées aux courtines, dont l'allure générale pourrait accuser plutôt le $\mathrm{XV}^{\mathrm{e}}$ siècle, époque d'adaptation précoce aux armes à feu.

\section{La tour nord-est, dite Tour ovale ou tour des Farines ( $\left.n^{\circ} 2\right)$ et les courtines adjacentes}

La Tour ovale, dite tour des Farines depuis $1932^{22}$, est l'unique tour flanquante conservée sur les sept qui garnissaient autrefois l'enceinte; elle est encore bordée au nord-ouest comme au sud par les courtines originelles, aujourd'hui totalement engoncées dans les parcelles habitées. Ces murs sont rectilignes, leur élévation interne ne présentant que des

Fig. 7 - Vernon, plans de la tour des Farines (dessin J.Mesqui). 


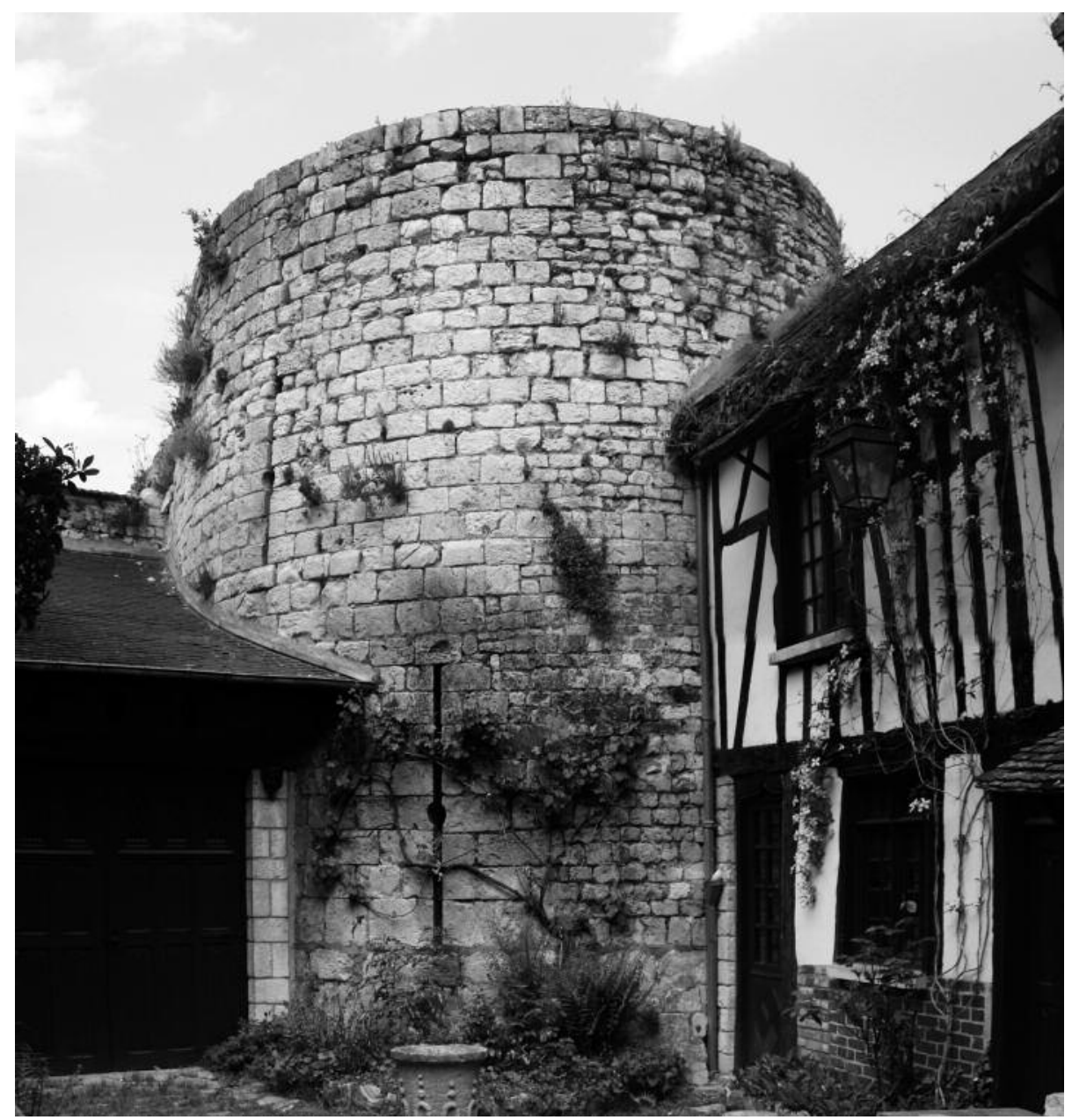

Fig. 8 - Vernon, vue de la tour des Farines prise depuis l'est.

faces en médiocre appareil assisé de moellons équarris.

De façon assez curieuse, il s'agit de la seule tour représentée comme cylindrique par le plan de $1779^{23}$; pourtant son plan est parfaitement elliptique ${ }^{24}$. Ses diamètres extérieurs sont d'environ $6,4 \mathrm{~m}$ par $8,5 \mathrm{~m}$; elle est entièrement saillante sur l'angle nord-est entre les courtines du château, ne débordant aucunement à l'intérieur de l'enceinte. On peut supposer que son tracé curieux a été causé par le souci de ne pas consommer trop d'espace dans le fossé vers le nord-est et la ville.

En partie cachée par les constructions adventices qui s'appuient sur elle, la tour présente extérieurement un parement en appareil moyen régulier sur sa moitié sud ; ce parement a été remaillé ultérieurement
Cl. J. Mesqui.

aujourd'hui à plus de trois mètres de hauteur. Le rez-de-chaussée de la tour, couvert d'un simple plancher, était pourvu de quatre fentes d'archères aux ébrasements couverts de dalles soutenues par des coussinets, dotées d'une plongée.

$\mathrm{Du}$ couloir d'accès, quelques marches conduisaient vers le sud à un escalier en vis dont ne subsistent que la base du noyau et les trois premières marches; la disparition de l'angle des deux courtines, sans doute au début du XIXe siècle, a conduit à des réparations de fortune, réalisées en mauvais appareil enduit de plâtre pour recréer un escalier et une porte à la salle du premier étage. Celle-ci est voûtée en coupole réalisée en mollons de petit appareil ; elle était pourvue de cinq archères couvertes de voûtes en plein cintre intersectant la voûte centrale, malheureusement extrêmement altérées.

\section{Éléments de datation}

Les caractères de cette tour sont extrêmement proches de ceux des tours du château royal de Guainville, construit à partir de 1192 pour faire pièce au château d'Ivry, à une trentaine de kilomètres au sud de Vernon ${ }^{25}$. On notera tout particulièrement le voûtement unique du premier étage par une coupole où s'insèrent les voûtes des ébrasements d'archères ; cette disposition se retrouve également à l'identique dans les tours du Diable et du Gouverneur de Gisors. Il est vraisemblable que Philippe Auguste mit en chantier cette tour, comme les autres tours de l'enceinte, très rapidement après la prise de possession de Vernon, soit dès le début de 1196.

On accède à la tour par un couloir aménagé à l'angle intérieur des deux courtines; malgré les nombreux remaniements qu'il a subis, on reconnaît sa voûte en berceau plein cintre et l'ébrasement d'une fente d'éclairage haut placée regardant le nord. À une époque inconnue, le sol du passage, comme celui de la tour, ont été abaissés par rapport au sol d'origine d'un mètre environ, de telle sorte que le linteau de la porte d'accès, soutenu par deux coussinets en quart de rond inversé, se trouve

\section{La Grosse tour, tour de la Cigogne ou tour des Archives $\left(n^{\circ} 1\right)$}

L'élément le plus spectaculaire du château est la tour dite, depuis le XIXe siècle, tour des Archives, du fait qu'elle abrita après la Révolution les archives de la ville. Elle était appelée couramment Grosse tour sous l'Ancien Régime mais semble également avoir porté le nom de tour de la 
Cigogne au début du XVe siècle ${ }^{26}$. L'édifice n'a été que très peu remanié depuis les années 1800, malgré les tribulations de son histoire moderne. On notera cependant une restauration consistant en des remaillages de pierres, intervenue en 1838-1840, concernant probablement la réfection complète du parapet sommital et la construction d'une dalle de béton armé, indépendante de la voûte du premier étage ${ }^{27}$.

Élévation extérieure et couronne de mâchicoulis

La tour était primitivement isolée des courtines ouest et sud, comme de l'enceinte urbaine qui partait au nord-ouest ; elle était défendue, côté cour du château, par un fossé propre qu'on voit figurer dans le plan de 1593, communiquant avec les fossés extérieurs du château, suivant une disposition coutumière dans les tours maîtresses de Philippe Auguste. Son diamètre extérieur s'établit à $11,44 \mathrm{~m}$ au niveau du sol extérieur ; la base enterrée était vraisemblablement pourvue d'un talus en glacis. Bien que, de loin, l'édifice donne une impression de grande homogénéité pour ce qui concerne ses parements, l'analyse rapprochée montre l'utilisation de deux types de pierres : celles qui forment l'encadrement des baies du premier étage sont en grand appareil, alors que le reste de la tour est en moyen appareil réglé, aux assises variables en hauteur. Cependant, il n'existe aucune raison de douter de leur caractère contemporain.

En revanche, les parties hautes de la tour ont fait l'objet de remaniements faciles à déceler (fig. 12). On décèle en premier lieu une assise marquée régulièrement par des blocs cubiques : ceux-ci résultent manifestement du bouchage des anciens trous de boulin d'un hourdage de bois qui garnissait le couronnement primitif de la tour (fig. 10). Au-dessus, on reconnaît par endroits la trace d'anciens créneaux mais la maçonnerie originelle a été remplacée par des grandes pierres formant l'encadrement de trois fenêtres rectangulaires qu'on décrira plus loin. Ces modifications sont contemporaines de la création d'une couronne de mâchicoulis à trois assises, ainsi que de la surélévation de la tour par un chemin de ronde assis sur cette couronne de mâchicoulis.

La date de réalisation de ce couronnement de mâchicoulis est fournie par une quittance datée du 6 mai $1415^{28}$; il a été construit alors que le péril anglais se rapprochait dangereusement et que l'on mettait hâtivement en défense les places normandes.
L'accès primitif et la distribution des étages

L'accès primitif à la tour se pratiquait depuis la courtine sud-est, au premier étage. On remarque encore sur l'élévation interne de cette courtine l'arrachement des marches de pierre qui conduisaient depuis le niveau du sol jusqu'à la portion de courtine placée face à la porte de la tour. L'escalier enjambait une ouverture voûtée ménagée dans la courtine (fig. 11),

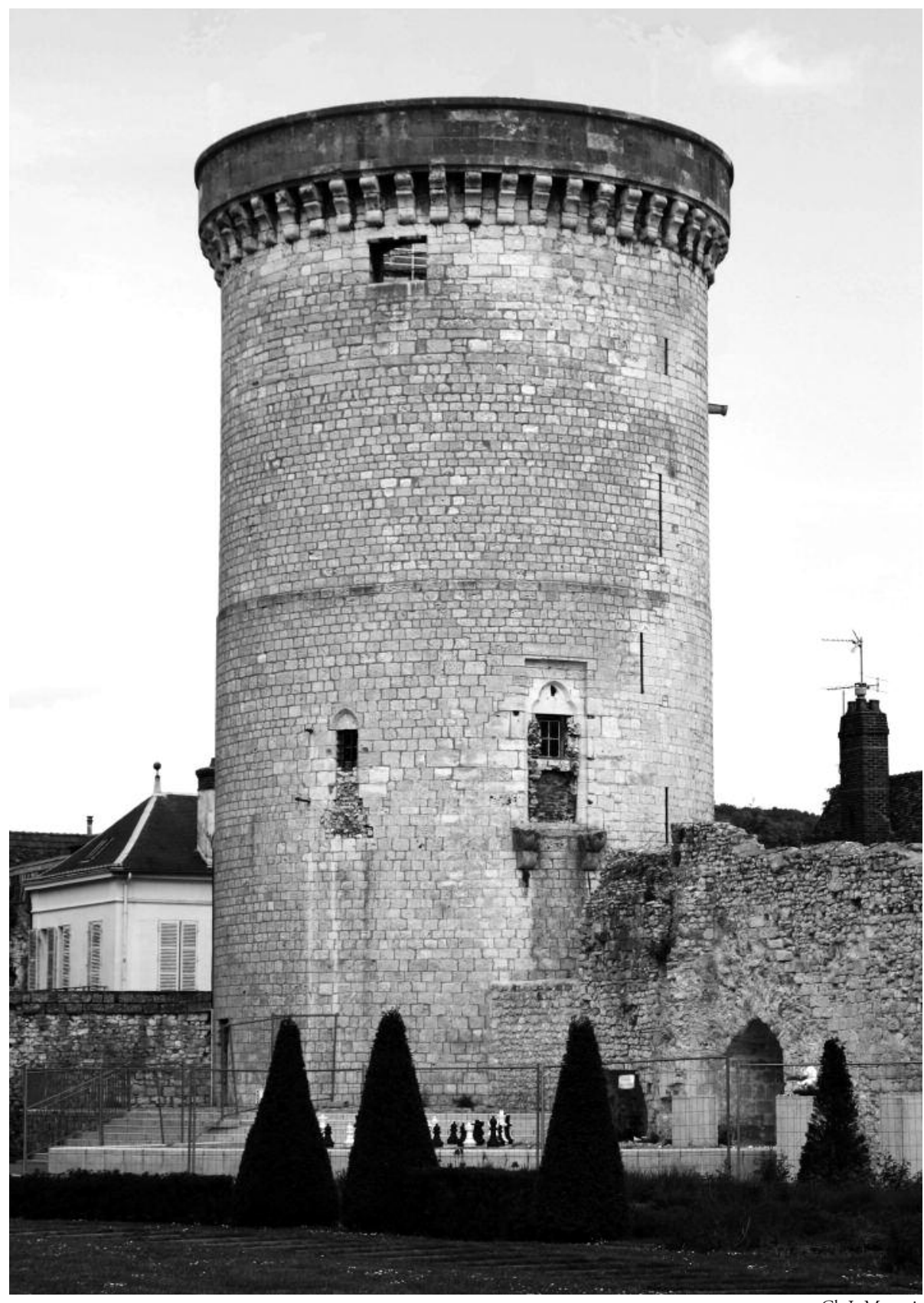

Fig. 9 - Vernon, la Grosse tour, vue depuis le sud-est en 2010.
Cl. J. Mesqui. 


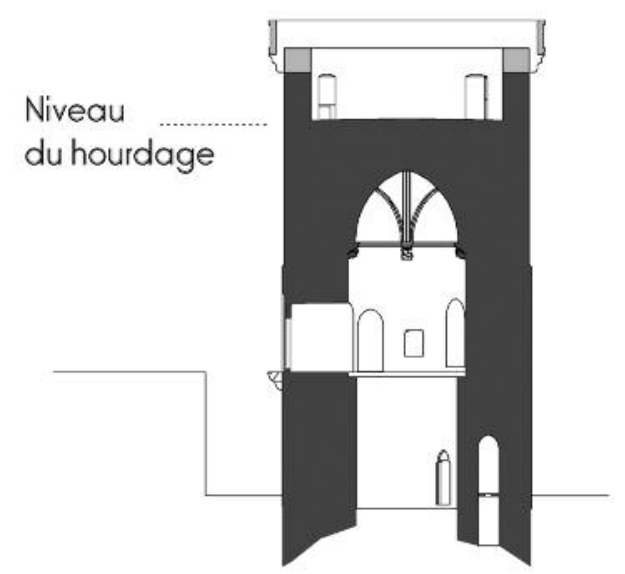

Coupe AA

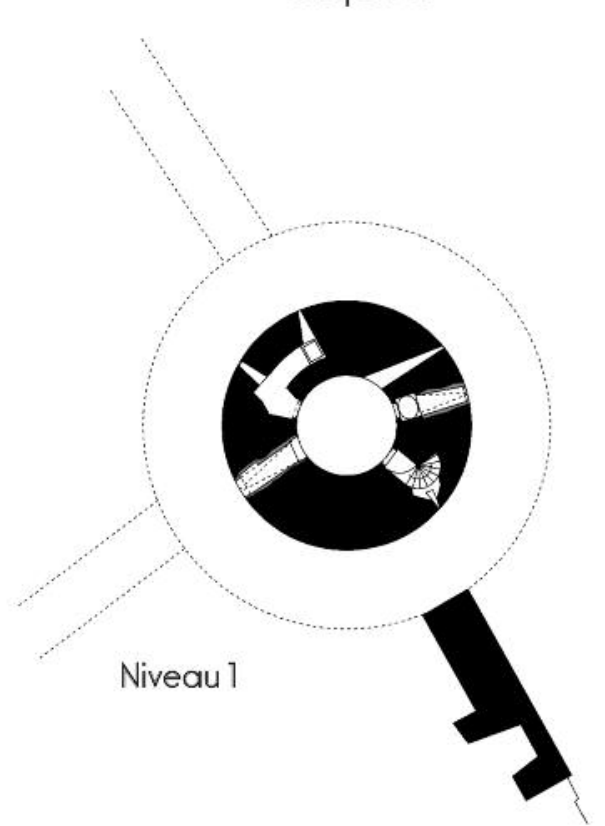

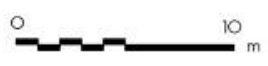

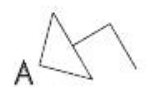

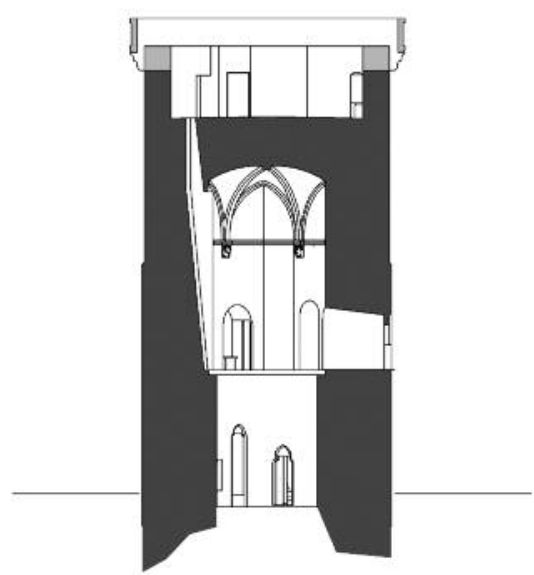

Coupe BB

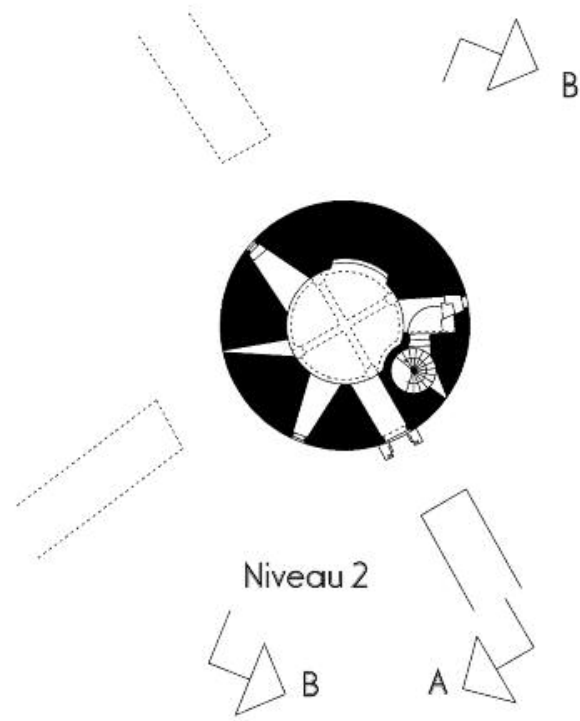

B

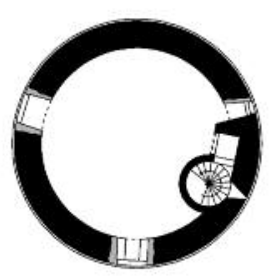

Niveau 3

Fig. 10 - Vernon, plans et coupes de la tour des Archives ou Grosse tour (dessin J. Mesqui).

peut-être une poterne donnant sur la rue Potard directement ; il s'appuyait sur un massif perpendiculaire à la courtine dont subsiste également l'arrachement.

De là, une passerelle menait à la porte de la tour. Il s'agissait d'un pont de bois pivotant sur deux consoles à deux assises qui ont été conservées ; le tablier venait s'insérer en position haute dans une feuillure rectangulaire dont la bordure haute était ménagée en quart de rond. La remontée s'en effectuait par une chaîne qui coulissait apparemment au travers du tympan de la porte elle-même de façon peu gracieuse (fig. 13).
La porte était décorée de façon peu usuelle dans une tour maîtresse royale : sa bordure décrivait une succession de courbes pour dessiner un trilobe se détachant de deux coussinets, encadrant un tympan plein aux faces indentées en escalier. La maçonnerie conserve par ailleurs les stigmates de fermetures à charnières modernes, encore visibles au début du siècle dernier.

On entrait ainsi dans un couloir voûté en berceau conduisant à la salle circulaire du premier étage, seul niveau voûté sur croisée d'ogives, d'un peu plus de neuf mètres de hauteur à la clef. Elle possède trois petites fenêtres rectangulaires dont les ébrasements externes se prolongent classiquement par des arcs brisés encadrant des tympans pleins, au fond de voûtes en plein cintre ou brisées ; il n'existait en revanche qu'une ouverture défensive, une archère à forte plongée couverte de dalles, aujourd'hui bouchée. Enfin, cet étage était pourvu d'une grande cheminée dont la hotte conique a disparu ; en revanche, le contrecœur d'origine existe toujours.

Dans l'ébrasement de la fenêtre orientale se trouve la porte conduisant à l'escalier en vis desservant les autres étages ; curieusement, la cage de cet escalier 


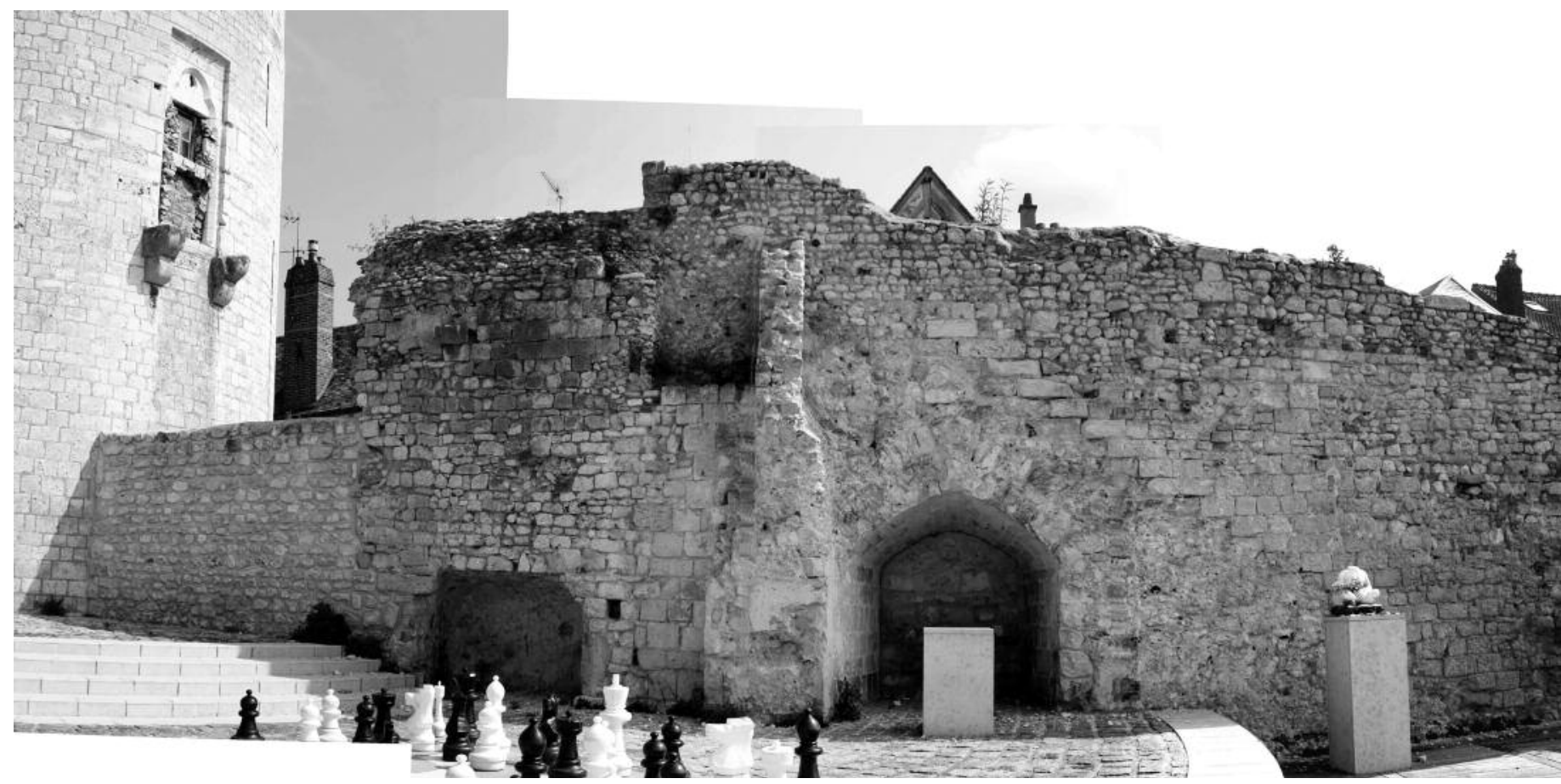

Cl. J. Mesqui.

Fig. 11 - Vernon, vue intérieure de la courtine sud-est du château. Noter l'arrachement de l'ancien escalier.

déborde légèrement dans la salle du premier étage, sans doute parce que l'architecte avait légèrement surdimensionné le diamètre intérieur de cet étage $(5,38 \mathrm{~m}$ contre 4,62 au rez-de-chaussée).
L'escalier en vis est à noyau portant marches, reposant sur un socle mouluré au niveau du rez-de-chaussée. La vis s'éclaire par des jours en archère ; l'ébrasement du premier d'entre eux, au rez-de-chaussée, a

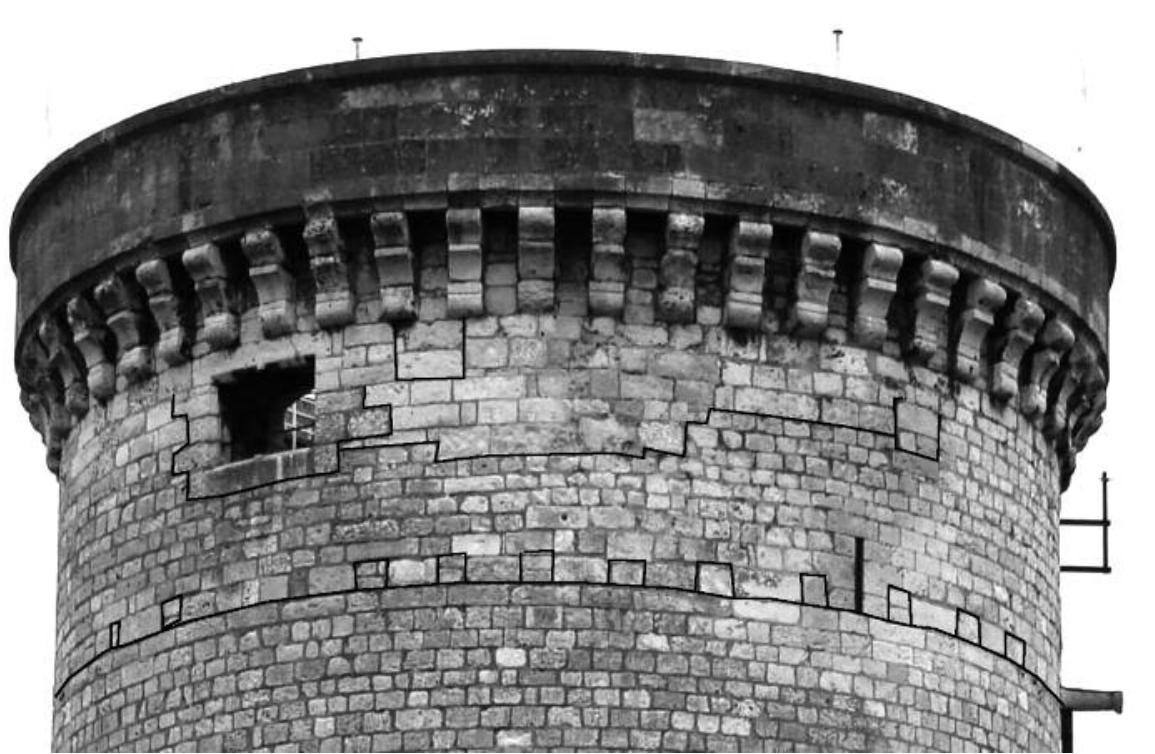

Cl. J. Mesqui.

Fig. 12 - Vernon, identification des reprises de maçonneries dans le haut de la tour (demicirconférence sud-est). En bas, ligne d'assise des poutres de l'ancien hourd; en haut à droite, trace d'un ancien créneau ; au centre, insertion de maçonnerie contemporaine de la fenêtre rectangulaire. été évasé au XV ${ }^{e}$ siècle afin de permettre la manœuvre d'une arme à feu dont demeurent les accroches latérales, la fente ayant été elle-même agrandie par un trou circulaire à mi-hauteur.

La salle du rez-de-chaussée pouvait être isolée par une porte fermant de l'extérieur, suggérant son utilisation comme cachot dès l'origine. Ceci est confirmé par la présence d'une latrine à fosse dans une petite chambre située à l'opposé de l'escalier en vis, pourvue d'une archère élargie en fenêtre et d'une petite fente d'aération couverte d'un plein cintre à côté du siège. C'est à ce niveau que se trouvait le puits de la tour, dans une haute niche voûtée en berceau, percée d'un jour élargi dans son mur de fond. Enfin, la salle possédait deux archères complémentaires à celle de la latrine, couvertes de dalles amorties par des coussinets en quart de rond inversé. L'archère sud-ouest a été élargie et transformée en porte d'accès moderne, l'accès originel du premier étage ayant été désaffecté.

Les deux portes médiévales, ainsi que la baie ouvrant sur le puits, ont reçu une décoration peu usuelle dans un niveau à 
vocation carcérale (fig. 13); chacune d'entre elles est, en effet, surmontée d'un trilobe encadrant un tympan plein décaissé.

L'escalier en vis permet de remonter jusqu'au deuxième étage ; on peut voir, peu avant d'arriver à ce niveau, grâce à un trou d'homme donnant dans l'escalier, un vide accessible entre l'extrados de la voûte du premier étage et la dalle de béton armé construite sans doute sous l'occupation allemande. Ce deuxième étage était, comme on l'a vu plus haut, le niveau supérieur primitif, pourvu d'un hourd de bois en encorbellement : les murs y sont donc

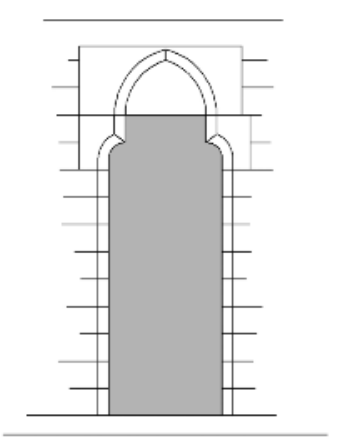

Latrine

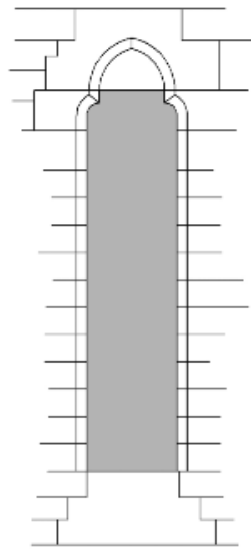

Puits

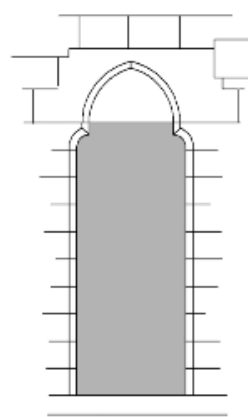

Escalier en vis
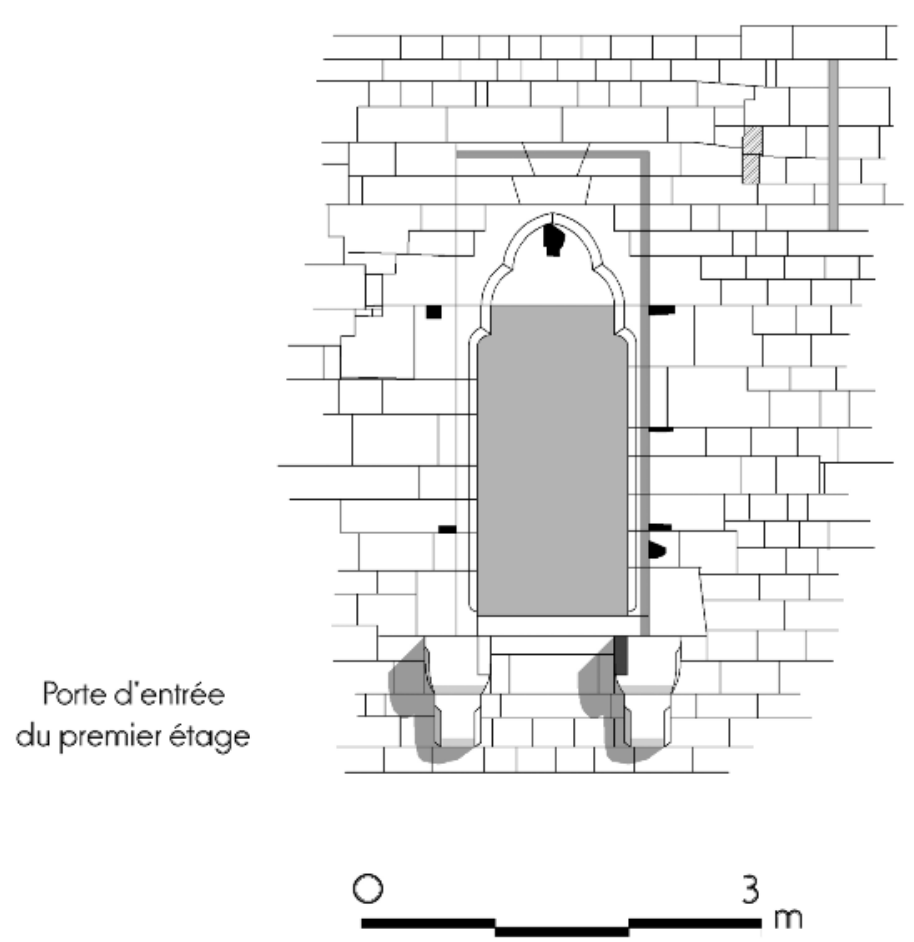

2. Mesgui 2010

Fig. 13 - Vernon, élévations des portes de la tour maîtresse (dessin J. Mesqui). En haut, portes intérieures du rez-de-chaussée. En bas, porte extérieure du premier étage de la tour, dans son état actuel. bien plus minces qu'aux étages inférieurs, la salle intérieure ayant un diamètre de $8,80 \mathrm{~m}$. Cet étage était couvert d'un toit à lucarnes, surmonté d'une "échauguette" consistant en un lanternon central ${ }^{29}$.

En 1415, le parapet fut modifié par le percement de trois fenêtres rectangulaires, dont deux à meneau, s'ouvrant au fond de niches pourvues de coussièges; il fut surélevé et pourvu d'une couronne de mâchicoulis supportant le nouveau chemin de ronde. Il ne semble pas pour autant que la toiture ait été refaite : la vue de la tour par Duviert au début du XVII ${ }^{e}$ siècle montre, en effet, que la toiture à lucarnes était entourée par le chemin de ronde à mâchicoulis qui était, quant à lui, à ciel ouvert (fig. 1).

\section{Les sculptures du premier étage}

La voûte sur croisée d'ogives du premier étage est quadripartite ; les arcs d'ogives ont un profil à double tore séparé par une simple gorge, alors que les arcs formerets sont constitués d'un tore unique. Ces arcs retombent sur des consoles rectangulaires aux tailloirs reliés par une corniche continue ceinturant la salle ; la particularité est ici que les tailloirs reposent sur des sculptures anthropomorphes de grande dimension, d'une qualité d'exécution et de conservation sortant de l'ordinaire (fig. 14). À droite de la cheminée, face à l'entrée de la tour, un personnage courbé semble amorcer un salut à l'entrant en posant la main sur son chapeau qui couvre sa chevelure bouclée ; le visage orné d'un bouc et d'une moustache est pourvu d'un nez légèrement camus, à la racine épaisse.

Cette sculpture tranche avec les trois autres consoles, qui représentent toutes des têtes juvéniles. À gauche de la cheminée, on a représenté un jeune clerc tonsuré, au visage encore poupin et aux joues bien pleines ; au-dessus de la porte, c'est le visage souriant d'un enfant de sept à huit ans, lui aussi bien en chair et à la chevelure bouclée. Enfin, la dernière console figure deux têtes d'adolescents aux traits plus découplés, le plus âgé souriant légèrement alors que le cadet regarde au loin. 

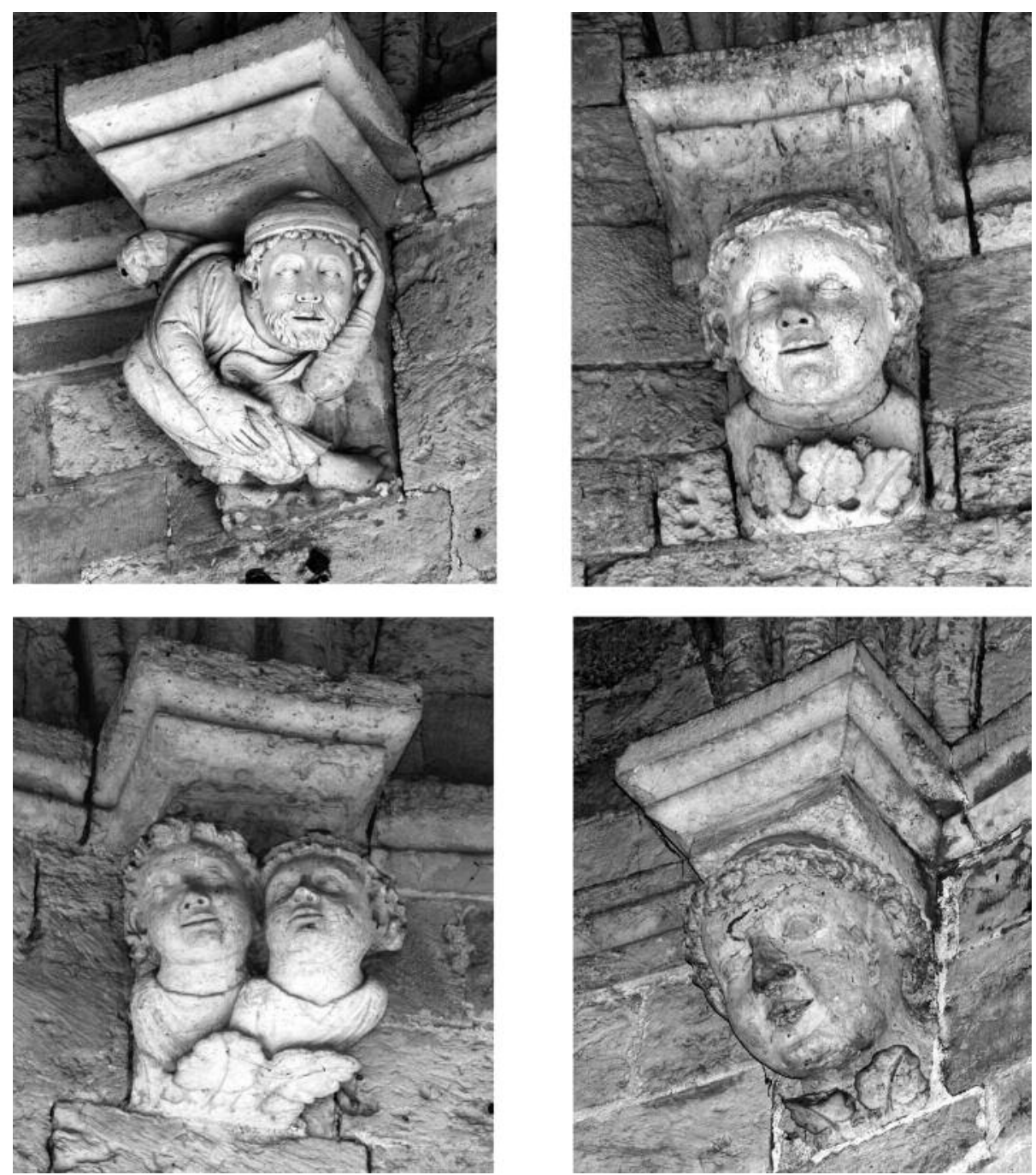

Cl. J. Mesqui.

Fig. 14 - Vernon, les quatre consoles sculptées du premier étage de la tour maîtresse. De gauche à droite et de haut en bas : nord-est, sud-est, sud-ouest, nord-ouest.

À ces quatre consoles vient s'ajouter une clef de voûte qui n'est guère plus usuelle dans une tour maîtresse (fig. 15) : en effet, le motif central est constitué par des feuilles de chêne délicatement sculptées, s'enroulant autour d'une fleur aux pétales déployés ; il est complété par quatre têtes de jeunes hommes aux cheveux longs, malheureusement assez érodées par rapport aux consoles de la voûte. L'un d'entre eux porte un chapeau, apparemment une barrette tricorne ; un autre porte un bonnet fixé par un ruban orné d'un joyau au-dessus du front, alors que les deux derniers ont les cheveux libres.

La datation de cet ensemble sculpté de premier ordre repose surtout sur la facture de la première console ${ }^{30}$. Le mouvement d'ensemble de celle-ci, la manière dont l'étoffe moule la jambe droite, les plis vallonnés du drapé s'arrondissant sur le ventre suggèrent un rapprochement avec le style en usage dans la sculpture des années 1180-1230 ; mais le crochet figurant audessus du personnage permet vraisemblablement de resserrer l'intervalle aux années antérieures à $1210^{31}$ (fig. 16). Les autres sculptures sont probablement contemporaines; cependant, les figures rebondies de ces enfants adolescents et de jeunes hommes tranchent avec les visages émaciés et allongés des sculptures contemporaines de l'art religieux, contribuant à donner l'image d'une société toute en bien-être et en quiétude, aux rejetons pleins de santé - presque de volupté.
S'il n'y avait guère de doute sur la datation de la tour de l'époque de Philippe Auguste, ces sculptures viennent le confirmer de façon éclatante ; on peut penser qu'elle fut mise en chantier dès la prise de possession royale et le fait qu' elle ne soit pas mentionnée dans le compte de 1202-1203 pourrait laisser penser qu'elle était terminée à cette date ${ }^{32}$. La fréquence avec laquelle Philippe Auguste résida à Vernon ${ }^{33}$ permet de penser qu'il donna lui-même les instructions relatives au programme sculpté ou, à tout le moins, que ce programme fut réalisé avec son accord express. Désira-t-il faire figurer des enfants et des jeunes gens de son entourage? Louis VIII avait 13 ans en 1200 mais il n'eut qu'une demi-sœur et un demifrère, Marie née en 1198 et Philippe Hurepel né en 1201, qui ne peuvent être les enfants figurés ici; de plus, on ne voit guère qui eût été le jeune clerc tonsuré s'il s'était agi de la famille royale. S'agissait-il alors d'enfants et d'adolescents présents à la cour de France ou ne doit-on voir dans cette série de têtes sculptées qu'une sorte d'allégorie ou de florilège ? La question demeure posée, comme celle de la coexistence entre ces sculptures figuratives et celle, plus symbolique ou plus humoristique, du personnage courbé saluant l'entrant.

\section{Un château vidé de sa substance depuis le XVIII siècle}

Au-delà de ces restes, dont certains sont prestigieux, rien ne demeure des anciens logis du château qui accueillirent rois et apanagistes; seuls le plan de 1593 et la vue de Chastillon peuvent donner une idée de ce qu'ils étaient vers 1600 - à vrai dire, le premier représente une série de bâtiments accolés aux courtines sans grande homogénéité, alors que la seconde met en exergue le grand et haut bâtiment situé à l'ouest, peut-être la grande salle. Quoi qu'il en soit, ceci n'autorise pas à restituer les bâtiments du Moyen Âge, que mentionnent quelques rares quittances qui émergent des Quittances et pièces diverses de la Bibliothèque nationale de France.

On peut donc considérer comme un petit miracle que la tour des Archives 


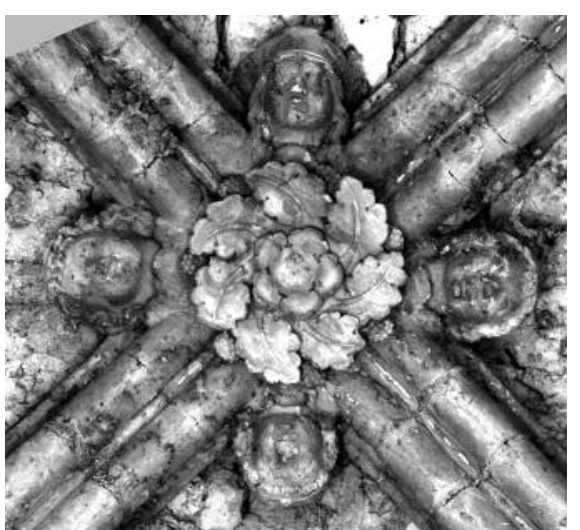

Cl. J. Mesqui.

Fig. 15 - Vernon, clef de voûte du premier étage.

ait survécu - malgré les velléités qu’eut la municipalité de la faire détruire au XIXe siècle - et si l'on peut avoir bien des doutes sur les qualités architecturales du " Jardin des arts " qui a été mis en œuvre dans l'ancienne cour intérieure du château, on souhaitera ici que les deux courtines restantes et la tour des Farines, ultimes vestiges de l'enceinte, soient classées et mises en valeur.

\section{LE « ForT DES TOURELLES »}

C'est en tant que « tour du pont » que le " fort des Tourelles ", appelé plutôt tour ou château de Vernonnet au Moyen Âge ${ }^{34}$, fait son apparition dans le compte royal de 1202-1203 ; elle y apparait comme confiée à la garde d'un certain maître Hugues ${ }^{35}$. Elle ne cessa, tout au long de l'Ancien Régime, d'appartenir au titulaire de la châtellenie de Vernon, qu'il s'agisse du roi ou de l'un des apanagistes ; le 18 décembre 1759, elle sortit néanmoins du domaine direct du titulaire, Charles-Louis-Auguste Fouquet, duc de Belle-Isle et de Gisors, au profit de JeanBaptiste Lemoyne de Bellisle, intendant du duc Louis d'Orléans, en tant que monnaie d'échange pour des terres que Lemoyne de Bellisle céda afin d'agrandir le domaine de Bizy ${ }^{36}$. Lemoyne de Bellisle, après l'avoir restaurée de fond en comble, l'affieffa par bail emphytéotique en 1765 à l'entrepreneur en meunerie Planter ${ }^{37}$.

\section{La disposition générale et l'enceinte sud}

Les plans dressés vers 1670 pour illustrer l'état du pont après sa chute et sa réparation partielle permettent d'en restituer la disposition ${ }^{38}$ (fig. 4 et 17) : un grand bras mort de la Seine délimitait une sorte d'île marécageuse traversée par la chaussée du pont, ouvrage constitué d'une sorte de longue digue percée de quatre petites arches. En aval de cette chaussée fut construite la fortification qui consista, jusqu'aux années 1760 , en une tour carrée flanquée par quatre tourelles circulaires, prolongée vers le sud-ouest par une enceinte rectangulaire rejoignant la Seine.

Cette enceinte rectangulaire, garnie à ses angles dominant la Seine d'échauguettes en encorbellement, fut transformée après 1765 en un haut bâtiment à trois niveaux en colombage, couvert d'un toit à deux niveaux de combles, qui servait d'entrepôt à grain pour la minoterie Planter ${ }^{39}$; il fut détruit après 1854 pour laisser place aux bâtiments d'une tannerie, eux-mêmes rasés à la fin du XIXe siècle ${ }^{40}$. Aujourd'hui, il ne demeure plus en élévation que la base talutée d'un mur de terrasse longeant l'ancien cours de la Seine, de direction sud-est - nord-ouest; il marque un retour au nord en direction de la tour et semble reprendre partiellement le tracé de l'ancienne enceinte, sans pour autant qu'on puisse le dater de façon certaine.

L'enceinte sud était accessible depuis la chaussée du pont par un pont dormant reposant sur une pile de pierre et un pontlevis. La première mention certaine trouvée dans les pièces comptables pour cet ouvrage date seulement de 1445 : en effet, on peut l'identifier avec le boulevard de la tour de Vernonnet dont on refaisait alors le pont-levis et le pont dormant ${ }^{41}$. Probablement existait-elle dès avant $14399^{42}$ mais elle devait être relativement récente puisqu'en 1377 il n'en est aucunement mention dans un récapitulatif de travaux, qui signale l'existence d'une salle pourvue de greniers et la construction d'une palissade en bois entre cette salle et la tour ${ }^{43}$.
L'ensemble était entouré de fossés en eau, signalés tout au long de l'Ancien Régime ; ils étaient déjà presque comblés du temps de Lemoyne de Bellisle qui dut les supprimer totalement ${ }^{44}$.

\section{La tour de Vernonnet. Les élévations externes}

Seule demeure en élévation la tour de Vernonnet elle-même, édifice de plan carré de $10,50 \mathrm{~m}$ de côté, flanqué par quatre tourelles circulaires de $6,3 \mathrm{~m}$ de diamètre, entièrement bâti en appareil régulier de calcaire de Vernon. Ses trois faces nordouest, nord-est et sud-est demeurent dans l'état immédiatement postérieur à la restauration menée en 1760-1765 par Lemoyne de Bellisle, ainsi que les tourelles qui les séparent.

Cette restauration, attestée par une inscription gravée sur une plaque de pierre en haut de la face sud-est ${ }^{45}$, est tout à fait remarquable dans sa qualité de mise en œuvre, presque indécelable sans un examen fin et rapproché : plusieurs anciennes archères ont ainsi été bouchées en partie ou

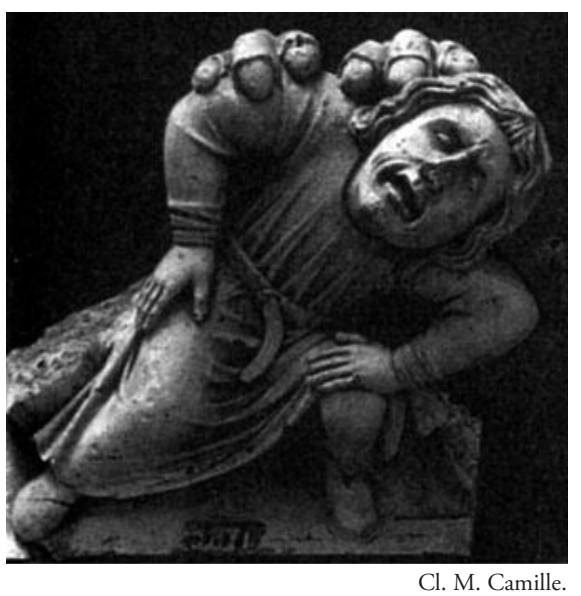

Fig. 16 - Laon, gargouille de la cathédrale (ancien moulage du Musée de sculpture comparée, voir note 31 ). On peut la comparer avec l'homme à barbe de la tour des Archives (fig. 14, en haut à gauche). Si la situation particulière des sculptures explique certaines de leurs ressemblances formelles - en particulier les torsions imprimées au corps, les similitudes dans l'arrangement des plis de la robe jusque sur le poignet, les yeux en amande au canal lacrymal affirmé, indiquent un même style et une même époque. 


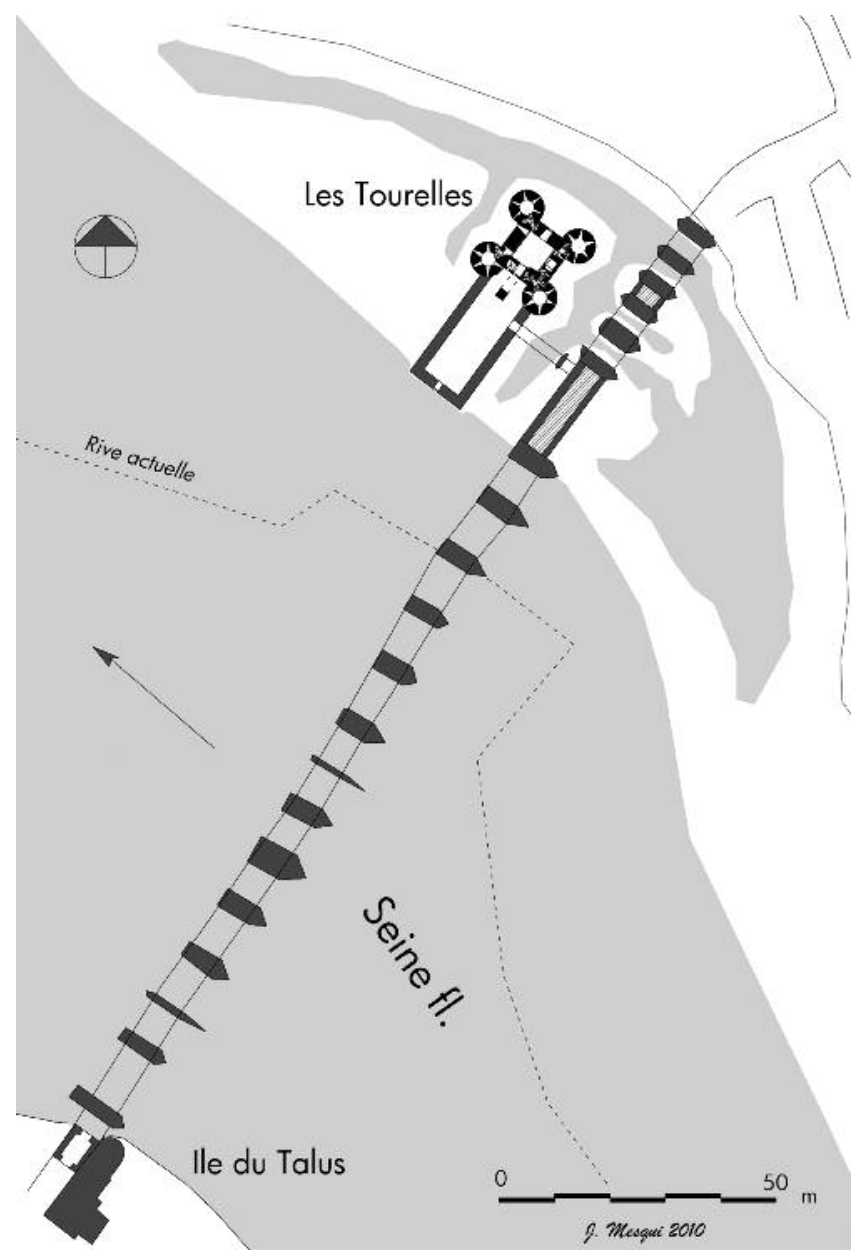

Fig. 17 - Vernon, plan de la seconde section du pont et du fort des Tourelles sur la rive droite dans son état restitué à la fin du XVII siècle, d'après le plan des années 1670 (dessin J.Mesqui).

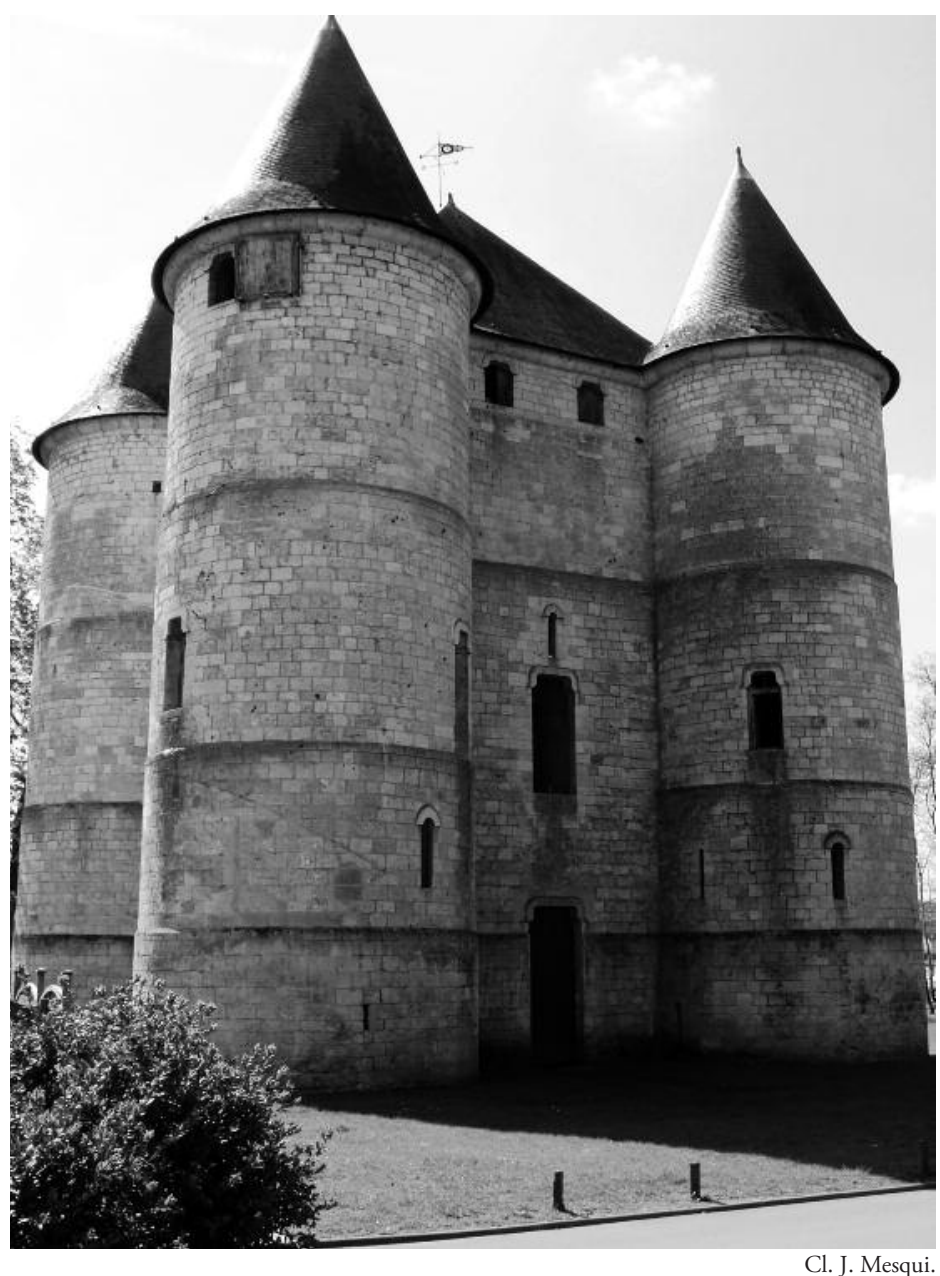

Fig. 18 - Vernon, fort des Tourelles, la tour, état actuel vu du nord-est. Noter au sommet de la tour orientale, au premier plan, le panneau de bois de l'ancienne horloge placée au XVIII siècle. en totalité, voire gommées, grâce à l'utilisation de pierres de même module et de même taille que les anciennes. L'architecte a procédé par ailleurs à la transformation de la majorité des ouvertures non bouchées ; les archères conservées ont été pour les unes élargies et surmontées de fausses archivoltes en bosse inspirées des anciennes, pour les autres transformées en fenêtres couvertes de linteaux échancrés décorés de larges moulures à angles arrondis (fig. 18 et 20).

On retiendra, de cette phase de restauration, les modifications fonctionnelles suivantes :

- percement dans la face nord-est de la tour d'une porte d'entrée au rez-dechaussée, et dans la tourelle nord d'une autre porte directe à ce niveau (fig. 18 et 20) ;
- percement d'une grande fenêtre dans la face nord-est, au-dessus de la porte d'accès (fig. 18) ;

- aménagement de la tourelle sud pour accueillir un escalier en vis monumental afin de desservir les étages (fig. 21) ;

- remplacement du couronnement primitif par un nouveau parapet crénelé supportant la charpente et le toit qui n'existaient plus depuis le début du XVII ${ }^{\mathrm{e}}$ siècle au moins ${ }^{46}$.

La transformation de l'enceinte sud en entrepôt à blé par aménagement d'étages au-dessus des maçonneries médiévales, qui intervint après 1765, fut menée de façon bien moins soignée que la restauration précédente. En effet, la façade sud-ouest et les tourelles attenantes furent repercées pour laisser place à des portes de commu- nication desservant les nouveaux planchers (fig. 20, fig. 21, fig. 24) ; de plus, des talons de maçonnerie verticaux furent ménagés le long des tourelles sud pour recevoir les murs de colombage de la surélévation. Contrairement à Lemoyne de Bellisle, qui avait veillé à ce que les reprises de maçonnerie soient les plus harmonieuses possibles, Jean-Michel Planter, dit Planter le jeune, tailla dans les maçonneries existantes sans avoir ce genre de délicatesse. Un peu moins d'un siècle plus tard, l'industriel Frédéric Ogereau, lorsqu'il eut fait détruire l'entrepôt de la minoterie Planter, aménagea des passerelles le long de la tour ouest ; c'est de son époque sans doute que datent les renforcements de maçonnerie par des poutres métalliques visibles dans la façade sud-ouest. 
Après la destruction de la toiture par les bombardements de la Luftwaffe en juin 1940 , une bombe alliée eut raison de la tourelle ouest le 6 août 1944. La tour fut reconstruite en deux étapes, d'abord en 1984 pour les deux niveaux inférieurs (architecte des Monuments historiques Guy Nicot), puis en 1997 pour les niveaux supérieurs (architecte des Monuments historiques Bruno Decaris) [fig. 20]. La première restauration a été menée en faisant du "faux ancien ", au point de marquer le départ primitif du mur de l'enceinte sud par un arrachement vertical dont on n'avait aucune certitude. Quant à la restauration de 1997, elle a été pour sa part menée sans restituer les ouvertures mais en intercalant entre les pierres de la partie haute de petites ouvertures carrées en plexiglas.

Les passerelles de la façade sud-ouest furent enlevées à la suite du bombardement de 1944, laissant béantes des ouvertures tant sur la façade que sur le côté de la tourelle ; ces ouvertures ont été bouchées de façon disgracieuse en 1997, sans doute dans l'attente d'une restauration définitive qui n'a pas eu lieu à ce jour.

\section{Le programme architectural primitif de la tour}

Le programme de la tour consistait en un pavillon carré de trois niveaux seulement - rez-de-chaussée, premier étage voûté sur croisées d'ogives, combles avec chemin de ronde, desservis par un escalier en vis situé dans l'angle sud, la cage débordant légèrement sur le volume intérieur des salles. À chacun des angles se trouvait une tourelle circulaire (fig. 21 et 24).

\section{Le premier étage}

La porte primitive de la tour se trouvait au premier étage, dans la face sudouest. Malgré les repercements et le

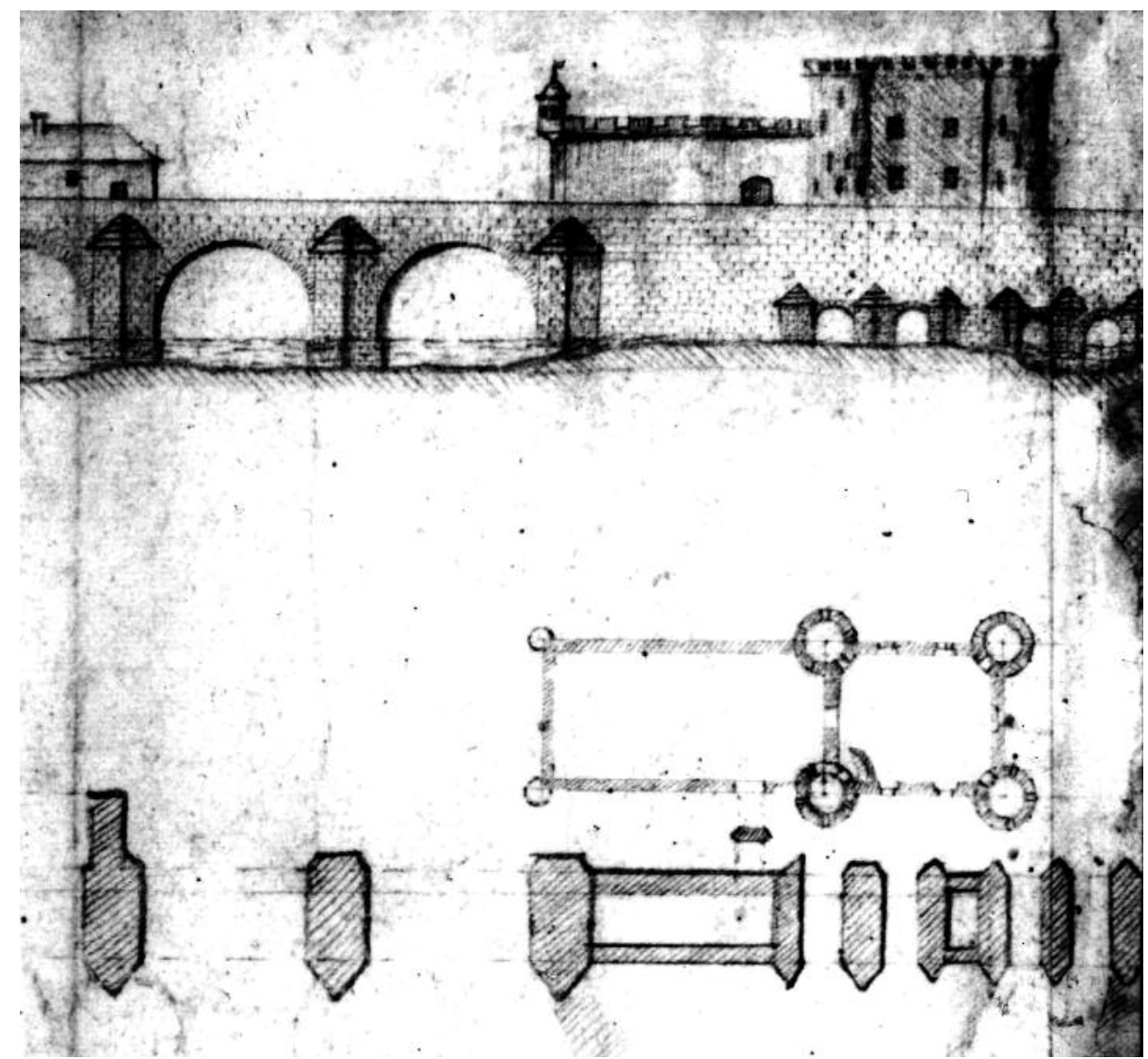

Fig. 19 - Vernon, plan et élévation du pont après 1658. Agrandissement sur la fortification de Vernonnet du plan reproduit en figure 4 . remplacement des maçonneries intervenus après 1765 , on matérialise encore fort bien tout le côté gauche (sud-ouest) de cette ancienne porte (fig. 22) et, intérieurement, les tableaux du couloir d'accès ; l'ouverture rectangulaire, surmontée d'un tympan semi-circulaire plein, était ménagée dans un encadrement rectangulaire où venait s'encastrer le pont-levis d'accès. On reconnaît même, au-dessus de la porte à gauche, une pierre semblant marquer l'issue de la goulotte où coulissait la chaîne permettant de remonter ce pont-levis, qui devait retomber sur une pile de pierre ou plutôt un bâti de bois ${ }^{47}$.

À gauche du couloir d'entrée se trouve un petit réduit rectangulaire couvert d'une voûte d'arêtes, dont le mur de fond a été bouché sans doute en 1765 et le mur de façade sud reconstruit plus récemment; la large ouverture, franchie par un linteau sur coussinets, en était primitivement fermée par une cloison délimitant la latrine de la tourelle ouest.

On débouche ainsi dans la salle du premier étage, la " haute chambre " ${ }^{48}$, formant un carré de 5,80 $\mathrm{m}$ de hauteur, surmonté d'une voûte sur croisée d'ogives montant à 8,20 m de hauteur. Cette salle possédait sur son mur nord-ouest une grande cheminée monumentale dont demeure une partie du contrecour originel, appareillé en tuileaux minces, disposés en couches appareillées en arêtes de poisson, séparées les unes des autres par un rang horizontal de tuileaux ; elle était encadrée par deux fentes de jour situées de part et d'autre. À l'époque de la minoterie Planter, la salle a été subdivisée en deux sousniveaux par un plancher intermédiaire en cohérence avec les niveaux adjacents de l'entrepôt.

L'éclairage était fourni par des fenêtres ménagées à l'intérieur d'étroites niches, hautes de 5,10 m et couvertes de voûtes en berceau brisé (fig. 24). Lors de la restauration de 1760-1765, les voûtes des niches ont été défoncées pour ménager des couvrements par des plates-bandes appareillées ; pour autant, leurs naissances ont été laissées en place dans les maçonneries, permettant d'en restituer le dessin. En revanche, aucune indication n'existe plus sur le type de 

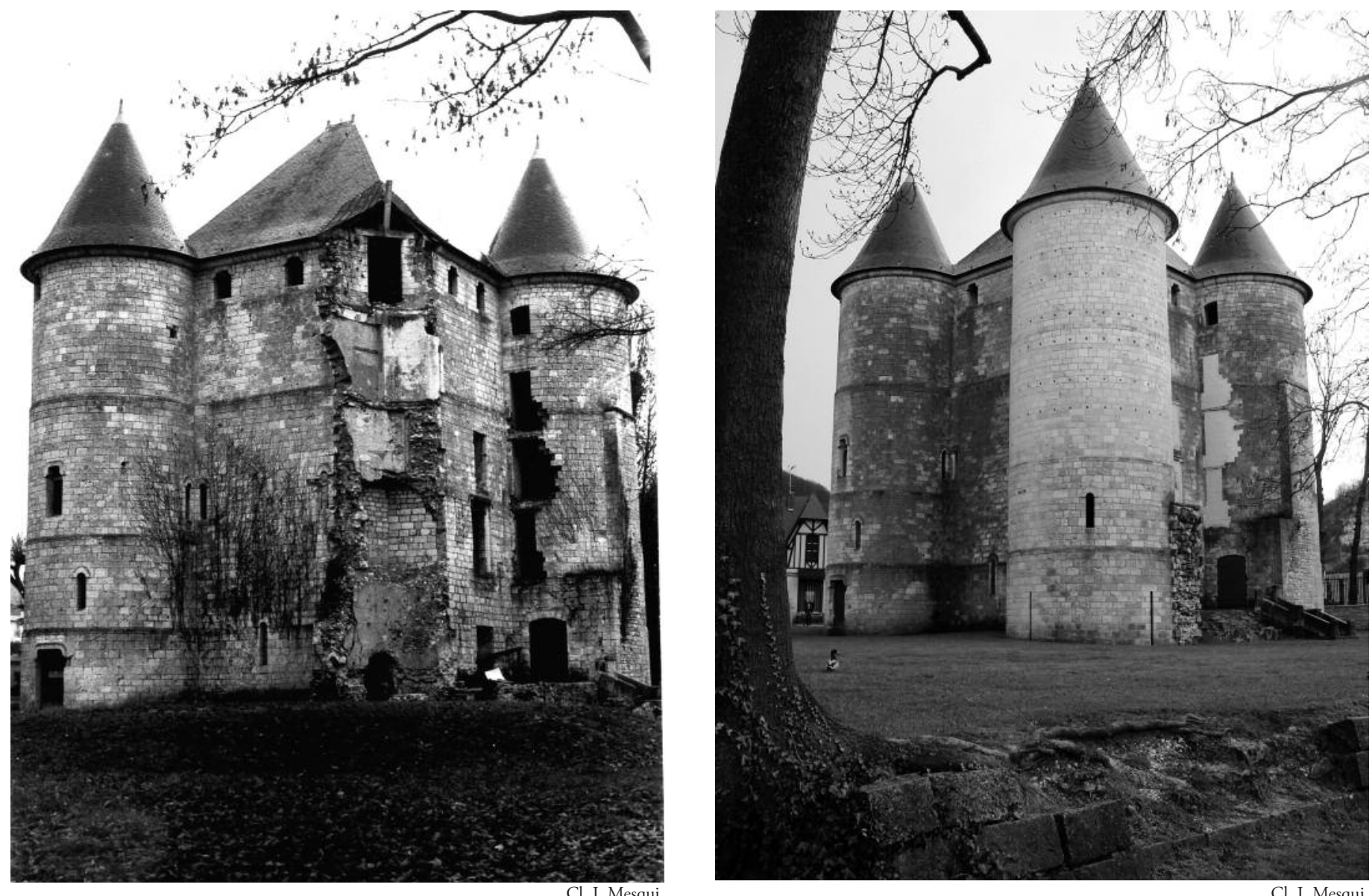

Fig. 20 - Vernon, fort des Tourelles, la tour de Vernonnet vue depuis l'ouest. À gauche, vue en 1973, à droite vue en 2010 après restauration de la tourelle ouest (deux premiers niveaux en 1984, le reste en 1996-97) et murage des ouvertures béantes.

fenêtres qui s'ouvraient au fond de ces niches ; au XVIII' siècle, une grande et haute fenêtre rectangulaire surmontée d'une fente de jour a été percée dans la niche nord-est, alors qu'au contraire, l'ouverture de la niche sud-est était remplacée soigneusement par une maçonnerie continue et un soupirail percé en haut de cette niche.

Dans les deux tourelles du côté nord, des couloirs voûtés d'arêtes et des petits escaliers permettaient d'accéder aux deux niveaux superposés d'entresol haut et bas ; seuls les entresols hauts étaient voûtés en coupole. Chacun de ces deux sous-niveaux était pourvu de cinq archères décalées d'un étage sur l'autre. L'intérieur des petites salles des tours a fait l'objet de remaniements considérables depuis 1760 jusqu'à l'abandon de la tour ; on distingue des aménagements liés à la transformation à usage d'habitation pour Lemoyne de Bellisle (amincissements de murs pour créer des surfaces planes, placards ou éviers dans les ébrasements d'archères).

Côté sud, vers la Seine, les dispositions étaient assez différentes : les murs des tourelles étaient nettement plus minces et les archères moins nombreuses. La ruine de la tourelle ouest et la transformation de la tourelle sud en escalier en vis - aujourd'hui condamné - empêchent malheureusement de restituer avec certitude les dispositions d'ailleurs profondément modifiées aux XVIII et XIXe siècles. On peut affirmer néanmoins que dans la tour ouest, le premier étage était de niveau avec la salle et qu'un couloir conduisait de la tourelle dans un réduit de latrines situé dans le mur sudouest, aujourd'hui accessible par le couloir d'entrée : la fosse de ces latrines existe encore au rez-de-chaussée, aujourd'hui simple renfoncement latéral dans le couloir d'accès sud de la tour, repercé au XIXe siècle. Il est probable que cette tourelle était celle désignée en 1377 comme contenant la chambre à coucher du châtelain ; symétriquement, on peut penser que la tourelle contenait la chapelle de la tour ${ }^{49}$.

\section{Le rez-de-chaussée}

Le couloir menant autrefois à la tourelle sud donne accès également à l'escalier en vis primitif, conservé sur toute sa hauteur ; cet escalier a été doublonné au XVIII ${ }^{e}$ siècle par la grande vis, aujourd'hui ruinée, aménagée dans cette tourelle sud qui a été condamnée de ce fait. La vis primitive est couverte par une voûte en berceau hélicoïdal rampant ; elle est éclairée par des fentes de jour ébrasées, couvertes de voûtes en plein cintre se prolongeant jusqu'à l'extérieur. Au niveau du rez-de-chaussée, elle donne sur un petit couloir d'accès qui pouvait être fermé par un vantail pour isoler la salle, prouvant que 


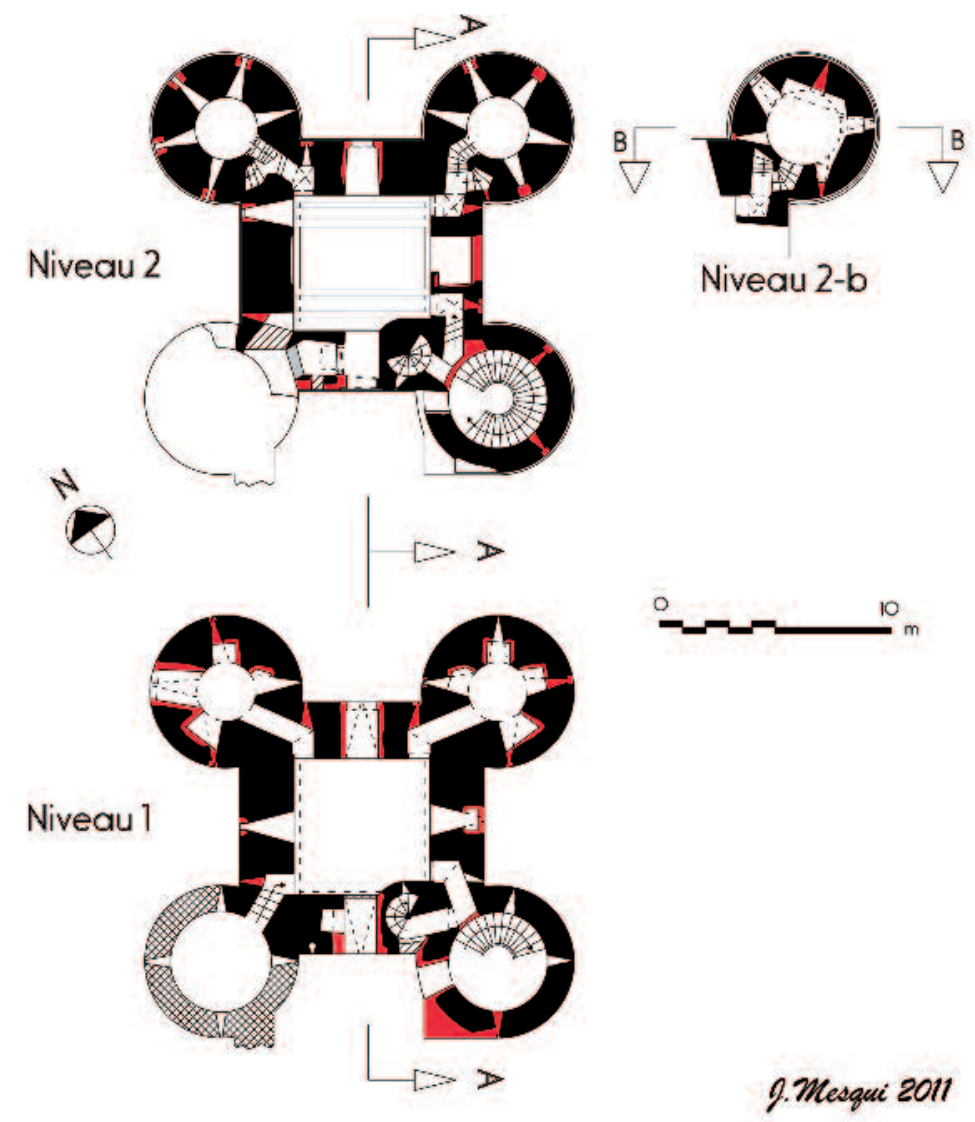

Fig. 21 - Vernon, fort des Tourelles, plans de la tour de Vernonnet (dessin J. Mesqui). En rouge, restaurations et transformations des XVIII et XIX ${ }^{e}$ siècles.

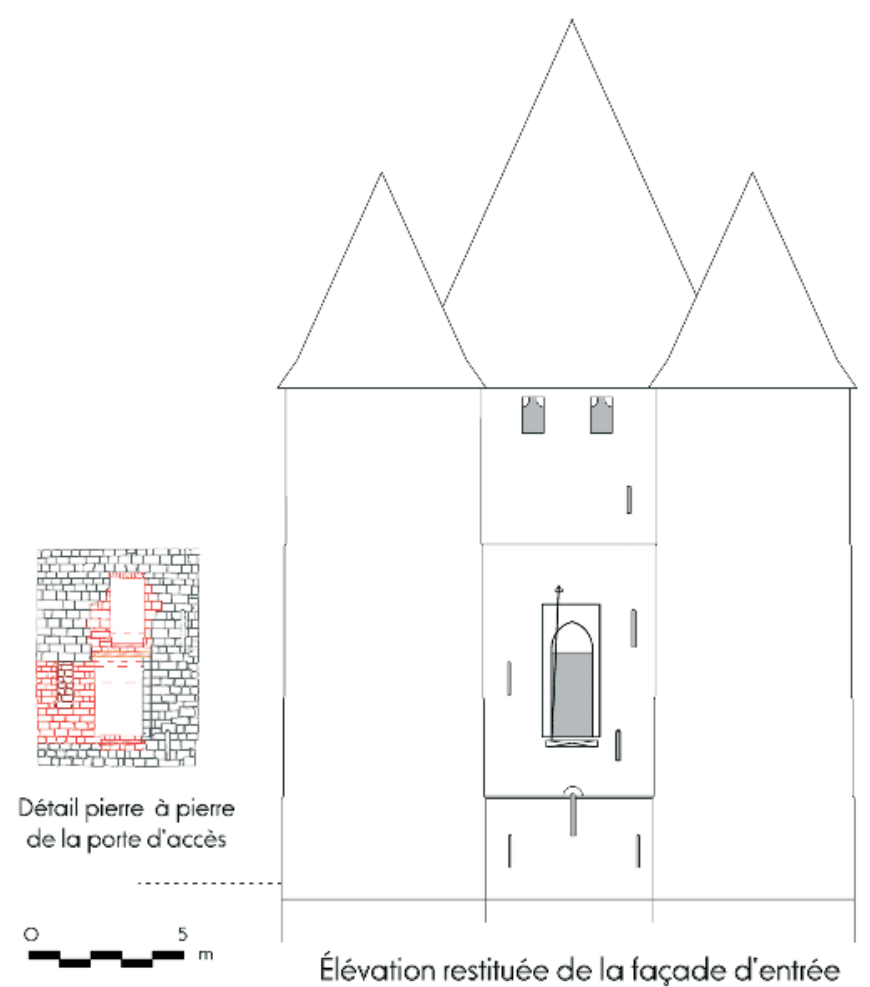

Fig. 22 - Vernon, fort des Tourelles, élévation de la face sud-ouest de la tour de Vernonnet (dessin J. Mesqui). celle-ci pouvait servir de prison ; l'ancienne fente de jour qui éclairait ce couloir a été repercée pour créer une porte à l'époque de Planter.

De là, le couloir perpendiculaire voûté de la tourelle sud, pourvu d'une archère, conduit à la salle du rez-de-chaussée. Celleci était couverte par un plancher dont subsistent sept solives courantes portant sur des corniches à deux assises en encorbellement ; devant la cheminée existait une trémie de $2,50 \mathrm{~m}$, limitée par un chevêtre sur lequel portaient deux solives bâtardes.

La salle était éclairée primitivement par une grande fente de jour dans chaque face, ménagée au fond d'un haut et spacieux ébrasement voûté en arc brisé. Les ébrasements du nord-ouest et du sud-est sont conservés mais seule la fente de jour du nord, repercée au XVIII siècle, subsiste aujourd'hui, sa symétrique ayant été murée ; les restaurateurs de 1760-1765 ont laissé néanmoins en place extérieurement le linteau en arc monolithe à bossage plat dit "à la florentine ", l'extrados étant en cintre brisé (fig. 23).

Depuis la salle, on accède aux tourelles par des couloirs voûtés : comme aux niveaux supérieurs, celles du nord sont pourvues d'archères à ébrasement simple couvert en berceau, alors que celles du sud, aux murs plus minces, n'étaient percées que de quatre archères chacune.

Il faut noter, avant de quitter ce rez-dechaussée, que le sol intérieur actuel est plus haut d'environ $90 \mathrm{~cm}$ que le sol primitif; il est aujourd'hui de niveau avec le sol extérieur nord, qui résulte lui-même d'un remplissage des anciens fossés. On ne trouve le niveau de sol intérieur originel que dans la tourelle ouest, par suite de la restauration de 1984. Cette surélévation intérieure a certainement eu pour cause l'intention de se mettre à l'abri du tout venant des crues de la Seine; elle a eu pour conséquence de diminuer la hauteur des ouvertures, obligeant ainsi à se courber pour accéder au couloir de l'escalier en vis. 


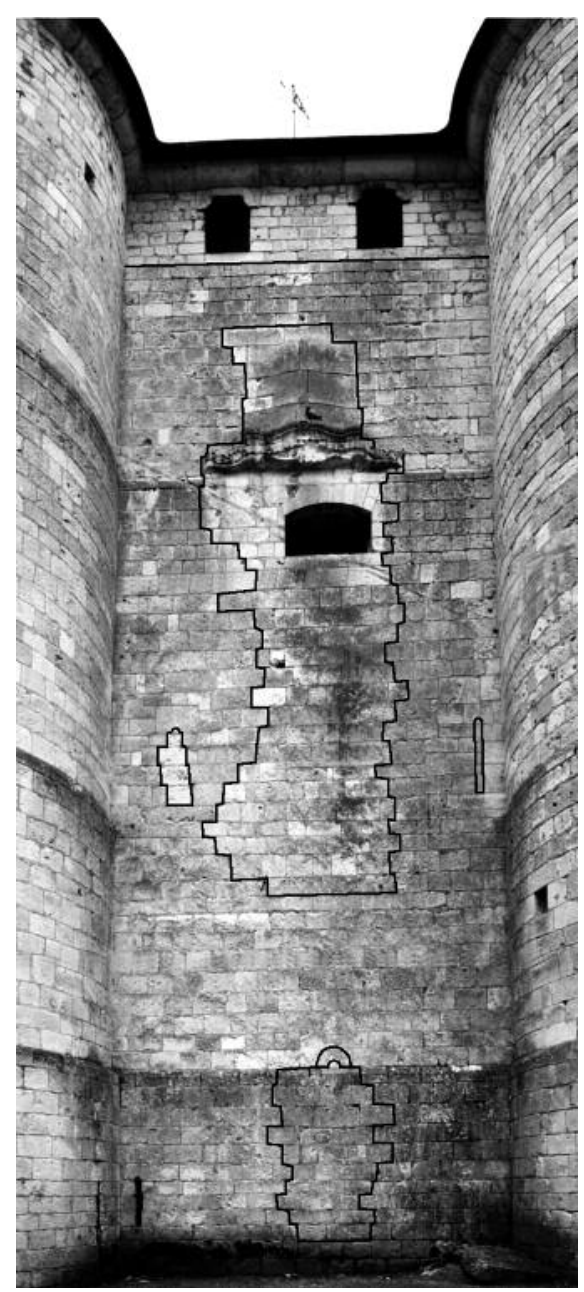

Cl. J. Mesqui.

Fig. 23 - Vernon, fort des Tourelles, face sud-est de la tour : visualisation des restaurations de 1760-1765.

\section{Le niveau sommital}

L'escalier en vis conduit vers le haut au chemin de ronde dont le parapet a été entièrement reconstruit en 1760-1765. Létat actuel consiste en une plate-forme chaulée établie sur l'extrados de la voûte du premier étage ; on note, au voisinage du débouché de l'escalier, une marche en remploi dans cet extrados, montrant que celui-ci fut remanié à de multiples reprises. Cette plate-forme est encadrée par les quatre tourelles; de façon très curieuse, les deux tourelles de la face nord présentent un niveau totalement aveugle au-dessus de l'extrados de l'entresol (fig. 24), inutile puisque inaccessible.

Ce niveau était couvert d'une charpente dès l'origine; la première quittance de travaux à l'attester date de $1373^{50}$. En 1377, la charpente fut entièrement démontée, puis remontée, afin de construire un " gariteis ", c'est-à-dire un hourdage défensif périphérique; après ce chantier, il fallut refaire la chape de plâtre couvrant l'extrados de la voûte et formant plancher pour le comble ${ }^{51}$. Il ne reste plus aucune trace des dispositifs d'encastrement de ce hourdage dans la maçonnerie : la ligne de trous de boulins carrés existant en partie sommitale de la face sud-ouest, seule trace d'un encastrement sommital, ne date que du XIXe siècle, marquant l'existence passée d'une toiture en auvent au-dessus des passerelles desservant cette façade.

Il est vraisemblable que le hourdage faisait partie du programme originel de la tour. Il avait disparu en tout cas au XVII siècle, de même que la charpente et la couverture d'essaune : à cette époque, Chastillon figurait un couronnement à mâchicoulis entourant un pavillon en retrait, alors que Duviert représentait un couronnement plat en terrasse, encadré d'un parapet haut percé de créneaux (fig. 1). L'élévation postérieure à la ruine du pont après 1658 représente, elle aussi, un couronnement à mâchicoulis ; cependant son exactitude est sujette à caution (fig. 19).

\section{Les sculptures du premier étage}

Comme la tour des Archives, la tour de Vernonnet offre en son premier étage un décor sculpté exceptionnel, malheureusement dans un état de conservation plus que préoccupant, à l'image de l'état sanitaire de la tour (fig. 25). Ce sont d'abord les trois culots sculptés supportant les retombées des arcs ogives : à l'ouest, il s'agit d'un chapiteau à crochets de facture assez sèche mais, en revanche, les chapiteaux de
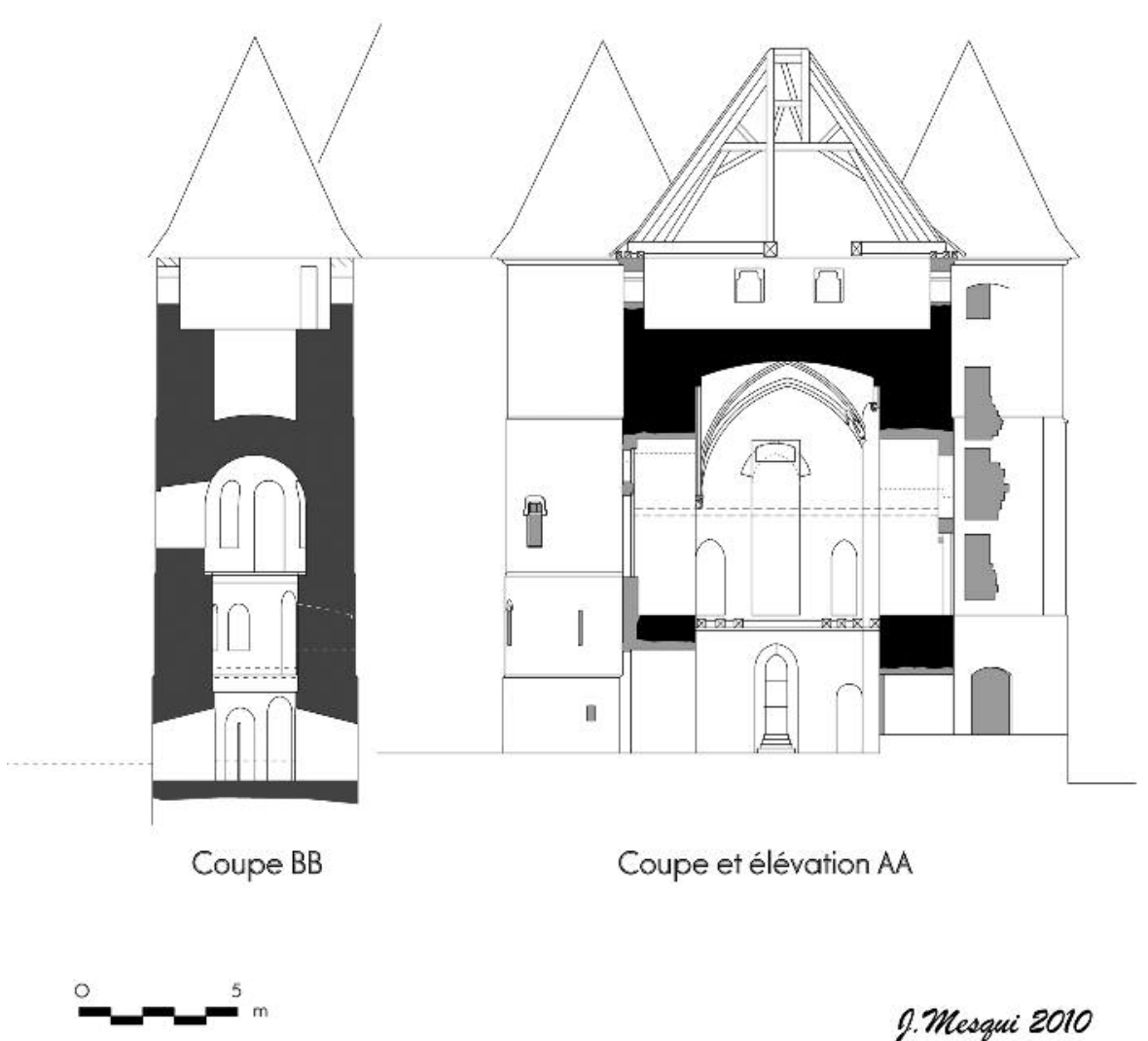

9. Mesqui 2010

Fig. 24 - Vernon, fort des Tourelles, coupes de la tour de Vernonnet (dessin J. Mesqui). 
la face nord sont figuratifs. Au nord, encadré par deux crochets, on trouve un personnage moustachu, aux pommettes proéminentes, couvert d'un chapeau à pointe encadrant sa chevelure bouclée; ses deux bras sont brisés mais il tenait l'un d'entre eux posé sur le genou, l'autre semblant brandir une arme. Au sud, c'est une tête de prophète ou de roi barbu et moustachu, couvert d'un bonnet côtelé orné d'une pierre, aux traits pleins et au nez épais, sous un front haut.

La quatrième branche d'ogive retombant sur la cage de la vis d'angle, il n'était pas possible d'aménager un culot pour accueillir sa retombée qui s'effectuait en pénétration ; en revanche, l'architecte accola à cette retombée la sculpture en pied d'un homme, privé de sa tête, terrassant un monstre. Le personnage s'appuie du dos à l'arc sur lequel il pose la main gauche; sa main droite, presque disparue, paraît appuyée sur une sorte de lisse horizontale allant rejoindre le formeret mais il n'est pas impossible qu'elle ait tenu une épée. Il est habillé d'une robe aux longs plis verticaux, maintenue par une large ceinture. Le monstre - sans doute une figure du diable - y est représenté de façon assez naïve, encore dans une inspiration romane ; le personnage se tient carrément debout sur son dos.

La sculpture était encore entièrement conservée en $1932^{52}$; elle a été décapitée depuis, sans que l'on en connaisse les circonstances. Alphonse-Georges Poulain notait seulement que cette tête était imberbe. Il est probable qu'il s'agissait d'une représentation de saint Michel terrassant le dragon : en effet, la tour de Vernonnet était située sous la protection tutélaire de la chapelle et du prieuré de Saint-Michel, situés à la pointe du plateau nord-est dominant la Seine.

L'ensemble sculpté comprend en outre un élément tout à fait particulier : une tête d'homme engoulant à pleines dents le tore d'un arc formeret, au coin ouest de la cage de l'escalier en vis. Il s'agit d'une fantaisie tout à fait étonnante de la part de l'architecte qui a dessiné ici une tête aux très longues oreilles et aux cheveux bouclés retombant dans le cou ; l'inspiration est ici à nouveau romane, rappelant les nombreux monstres ou diables engoulant des colonnettes aux encadrements de baies d'églises, mais l'utilisation du motif dans un tel contexte demeure inédite. Enfin, la clef de voûte était, elle aussi, délicatement sculptée de feuilles allongées s'allongeant en spirale autour du centre, alors que les angles entre les arcs ogives sont occupés par des têtes humaines aux pommettes proéminentes et aux traits marqués, malheureusement assez fortement abîmées par les dépôts liés à l'humidité et aux suintements.
Ces sculptures sont évidemment de même type que celles qui décorent la tour maîtresse, sans pour autant être nécessairement de la même main, ni répondre à la même inspiration. L'exécution révèle des différences appréciables : ainsi le profil des ogives dessine-t-il un tore en amande aux Tourelles, alors qu'il est circulaire aux Archives; le profil des tailloirs de culots est nettement plus sophistiqué aux Tourelles, alors qu'en revanche les feuilles de chêne utilisées aux Archives pour amortir la transition entre chapiteau et mur n'y apparaissent pas.
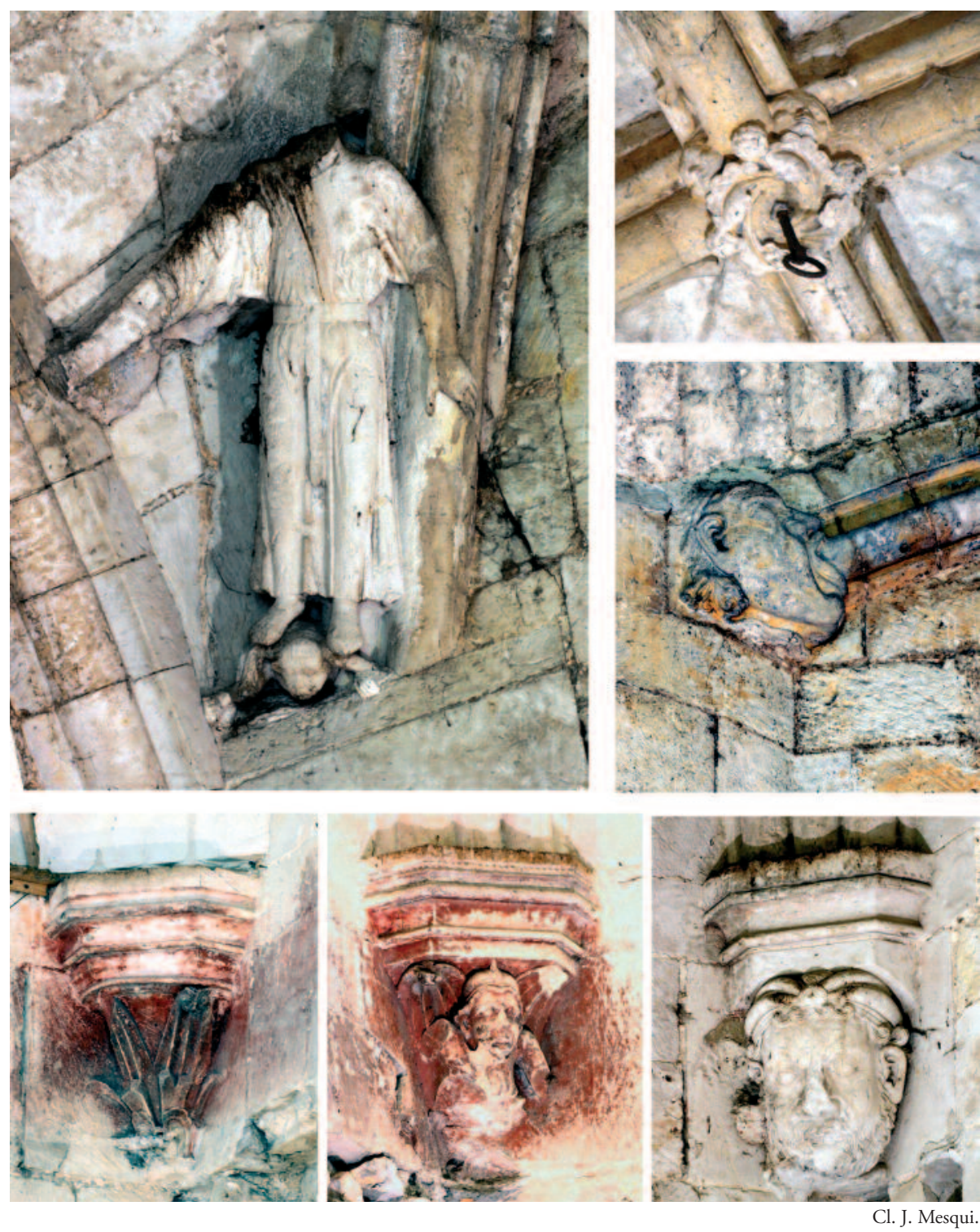

Fig. 25 - Vernon, fort des Tourelles, sculptures de la tour de Vernonnet. De gauche à droite et de haut en bas : La grande sculpture en pied à la naissance de l'ogive sud ; la clef de voûte ; le visage engoulant le tore de l'arc formeret sud-ouest ; la console ouest ; la console nord ; la console est. 
L'inspiration est radicalement différente : alors qu'à la tour des Archives est privilégiée une représentation quasi intimiste de personnages du quotidien d'une cour noble, celle de la tour de Vernonnet parait plus symbolique et d'essence peutêtre moins courtoise en apparence. Pour autant, dans l'une comme dans l'autre, on trouve un personnage énigmatique à l'allure presque grotesque représenté en entier sur un chapiteau - le sens nous en échappe malheureusement.

Hors contexte historique, ces différences pourraient inciter à dater la tour de Vernonnet de quelques bonnes années après son vis-à-vis de rive gauche. Cependant, la coexistence dans cette tour d'un gothique déjà bien ancré dans le début du XIII siècle, avec des usages du siècle précédent - vis à voûte hélicoïdale sur couchis, linteaux d'archères en arcs monolithe à fausse archivolte en bosse- montre qu'il convient d'être prudent sur l'utilisation de critères trop différenciant les deux tours. La mention explicite d'une tour de tête de pont dans le compte de 1202-1203 ne laisse guère de doute : il s'agit bien de la tour que nous examinons.

\section{LES RESTES DE L'ENCEINTE URBAINE}

Il resterait, avant de tenter de replacer les ouvrages vernonnais dans le contexte de leurs contemporains, à décrire les ouvrages de l'enceinte urbaine ; ceux-ci sont importants encore malgré la destruction quasi systématique qui a eu lieu au XIX ${ }^{e}$ siècle. En fait, de longs éléments de courtines ont été préservés lorsqu'ils constituaient des limites de propriétés mais cette situation leur a souvent valu de subir des restaurations ou des transformations; certains forment des alignements encore spectaculaires, comme au sud-est près de la route de Paris, ou au nord-est au voisinage du château, le long de la rue Potard.

On se contentera ici d'évoquer ces restes encore en élévation, qui appartiennent tous à la première enceinte urbaine. Celle-ci était, sur tout son tracé ne regardant pas la Seine, constituée d'une muraille de plus de deux mètres d'épaisseur, percée continûment de grandes niches d'archères doubles dotées d'une légère plongée. Cette disposition permettait d'obtenir une capacité de couverture de tir extrêmement importante, tout en économisant fortement le matériau grâce aux arcatures. À l'inverse, ce percement régulier au travers d'un mur assez mince $(1,2 \mathrm{~m})$ avait pour grand désavantage d'affaiblir considérablement la muraille.

Ce type de défense, certainement attribuable au XIII siècle, ne semble guère dans la lignée de la fortification de Philippe Auguste, où les courtines ne sont quasiment jamais percées d'archères, si ce n'est dans les parapets de chemins de ronde. On peut s'interroger si cette enceinte, avec ses percements, ne remonte pas audelà du règne de saint Louis et l'on peut même proposer, plus prudemment, une datation dans la seconde moitié du XIII ${ }^{\mathrm{e}}$ siècle, en comparant par exemple avec une grande enceinte urbaine telle que celle d'Aigues-Mortes.

L'homogénéité remarquable des vestiges de la première enceinte visibles au sud-est et au sud-ouest sur de longues sections montre que la partie terrestre de celle-ci fut édifiée en une seule campagne. En

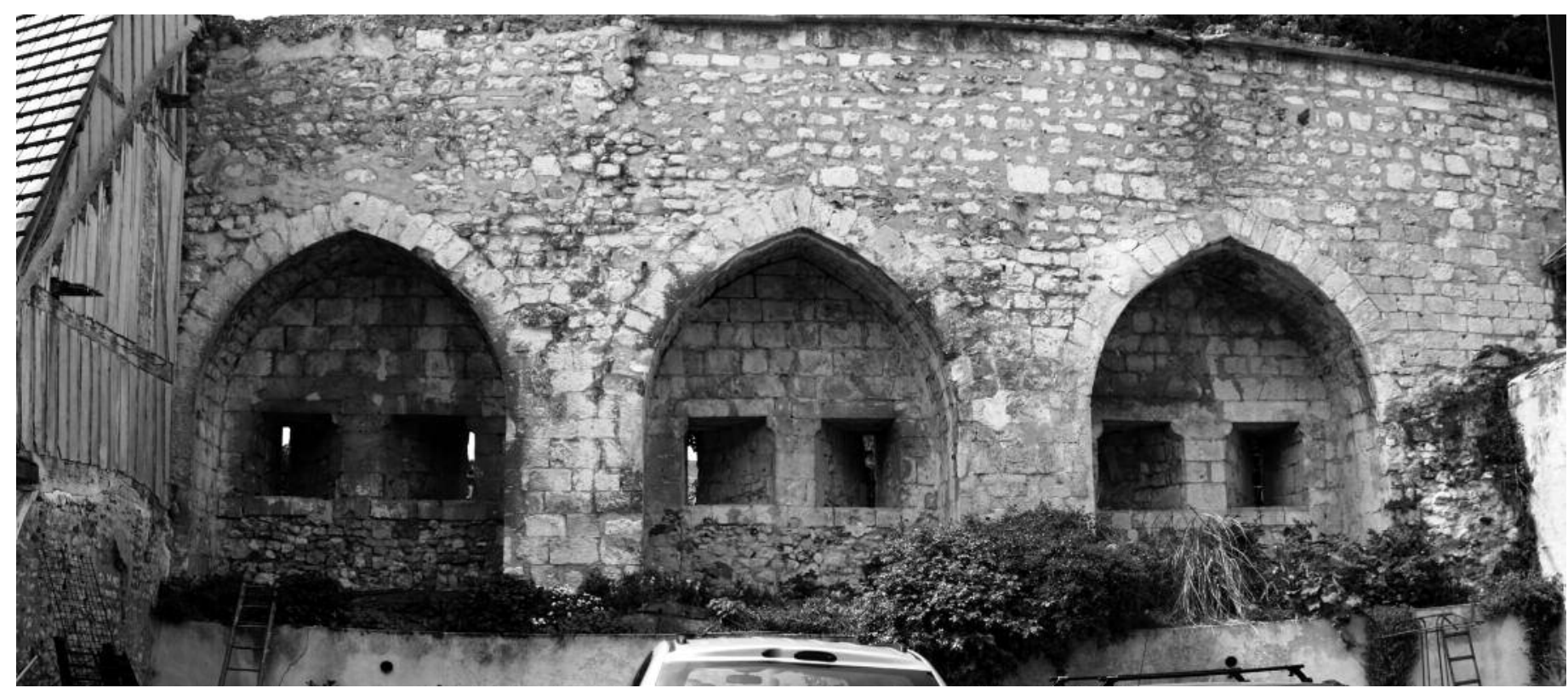

Fig. 26 - Vernon, enceinte urbaine, vue intérieure le long de la rue Potard, au nord-est. 
revanche, on sait par d'anciennes photographies ou descriptions que la partie longeant le fleuve, ainsi que la seconde enceinte, furent le fruit de restaurations ou reconstructions mais leur étude relève d'un autre article ${ }^{53}$.

\section{LES OUVRAGES VERNONNAIS DANS LA PRODUCTION ROYALE CONTEMPORAINE DU DÉBUT DU XIII ${ }^{\mathrm{e}}$ SIÈCLE}

\section{L'architecture}

Les tours de Vernon comptent donc parmi les ouvrages royaux les plus certainement attribuables à la décennie 11901200, plus précisément encore à la charnière entre XII ${ }^{\mathrm{e}}$ et XIII ${ }^{\mathrm{e}}$ siècles. Elles ont été élevées probablement alors que s'achevait, un peu au sud-est, le chantier du château de Guainville édifié à partir de 1192 sur les anciennes terres de Simon d'Anet, récupérées par le roi ; ces deux chantiers sont donc les premiers d'une série d'autres que le roi allait développer sur ses terres normandes à partir de la conquête de 1204. Pour autant, il y eut certainement d'autres chantiers royaux dès avant cette décennie - seul l'un d'entre eux est attesté, celui de la tour Neuve de Bourges qui était terminée en 1190, mais je pense pour ma part que la tour du Palais de Paris avait été lancée à la même époque et que ces deux tours furent les premières à marquer le territoire d'un roi, parti désormais vers une guerre totale de conquête ${ }^{54}$.

La tour maîtresse que le roi fit construire à Vernon, première ville normande qui lui appartienne en propre, à la suite d'un échange qui en faisait le propriétaire légitime en dehors de toute conquête, fait figure d'exception dans la série de 25 tours que nous avons recensées en France ${ }^{55}$. Elle était l'une des plus petites en diamètre mais ce n'était pas là son caractère discriminant, puisqu'elle n'était pas si loin de celle du Palais de Paris : 11,4 m pour $12,7 \mathrm{~m}$ de diamètre extérieur, $5,4 \mathrm{~m}$ pour 5,6 $\mathrm{m}$ de diamètre intérieur. On rappellera que la tour de Bourges, la
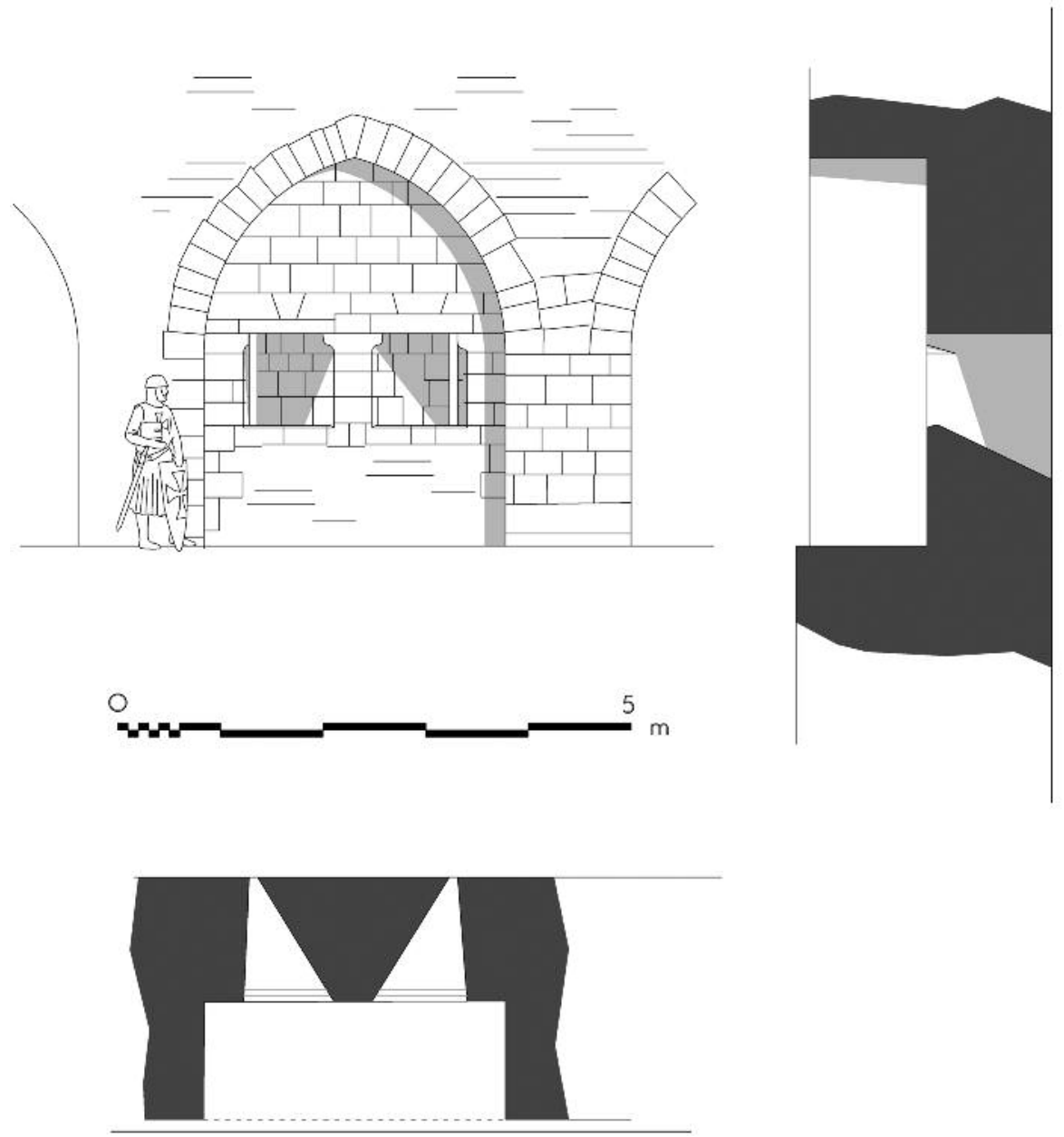

Fig. 27 - Vernon, enceinte urbaine, plan, élévation et coupe d'une archère type (dessin J. Mesqui).

première mentionnée par les textes, fut la plus vaste de toutes les tours royales (19,8 m de diamètre extérieur pour 9,5 m de diamètre intérieur) ${ }^{56}$.

C'est avec la tour de Vernon que semble, en revanche, apparaître pour la première fois le concept de tour maîtresse isolée sur une enceinte, avec la particularité insigne d'un isolement tant par rapport à l'enceinte de ville qu'à celle du château. À Bourges, la tour était tangente intérieurement à l'enceinte gallo-romaine mais fut entourée par une petite enceinte propre peut-être bien plus tardive; au Palais de Paris, comme au début du XIII ${ }^{\mathrm{e}}$ siècle au Louvre, la tour fut construite isolée à l'intérieur et non sur le pourtour de l'enceinte.
L'accès de la tour par la courtine n'est pas non plus la moindre des particularités, la majorité des tours maîtresses royales étant accessibles depuis la cour du château ou depuis l'intérieur de la ville, au niveau du sol. On trouve cependant une disposition analogue à la tour du Prisonnier de Gisors, sans doute contemporaine de celle de Vernon - elle ne dut pas être antérieure au traité du 14 janvier 1196, même si Gisors avait été conquise en 1193 par Philippe Auguste; dans ce dernier cas cependant, elle n'était pas isolée de l'enceinte castrale et sa position par rapport à l'enceinte urbaine était très particulière, en surplomb très marqué.

Enfin, le programme de distribution intérieure est exceptionnel, avec un très 


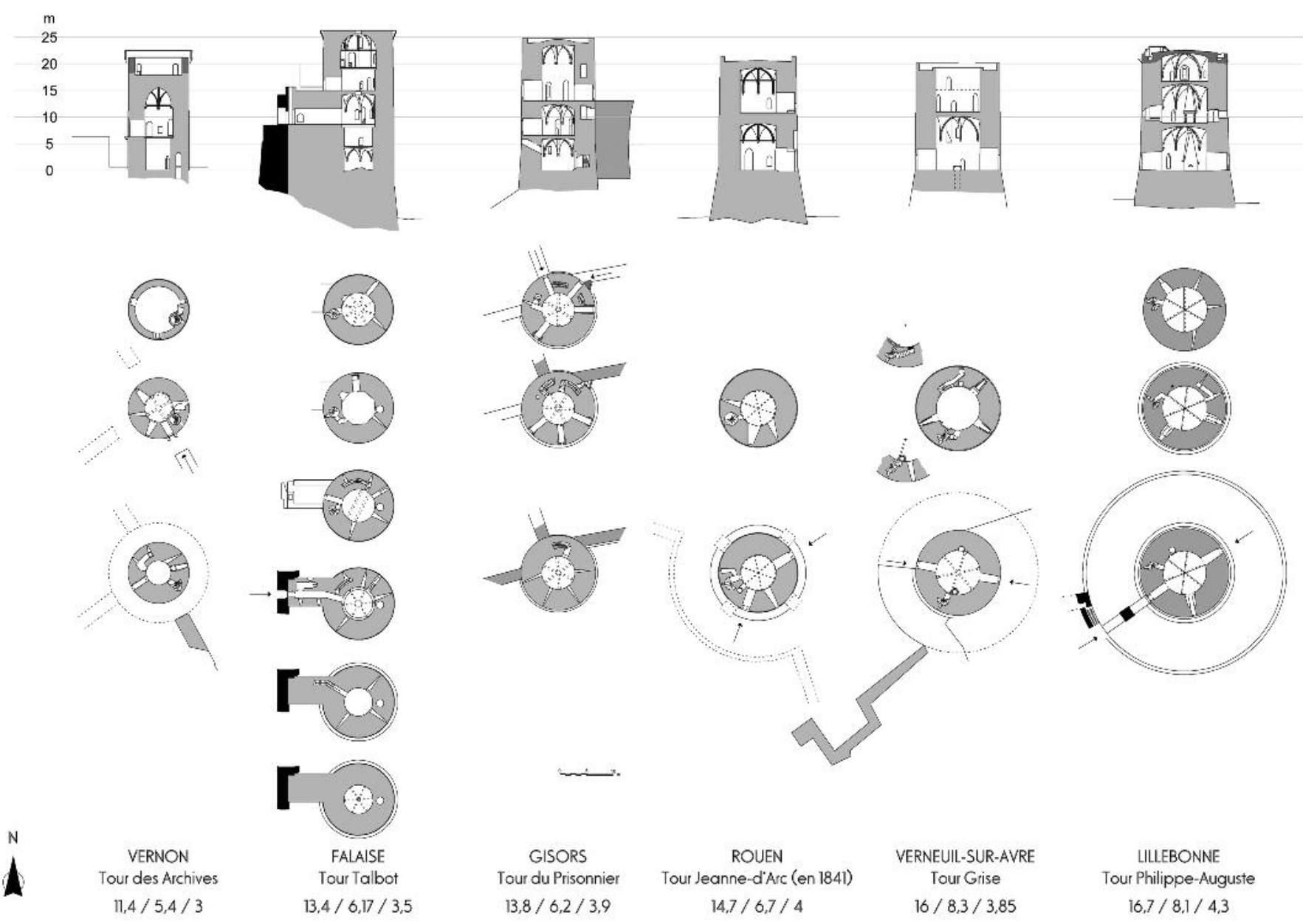

Fig. 28 - Vernon, plans et coupes comparatifs des tours maîtresses «philippiennes » en Normandie (dessin J. Mesqui).

grand étage voûté à la décoration sculptée remarquable, au-dessus d'un rez-de-chaussée planchéié pourvu de latrines et d'un puits. Le caractère unique d'un tel décor, ainsi que sa qualité qui s'étend jusqu'aux linteaux surmontant les portes, montrent qu'il fut prévu et mis en place à l'attention personnelle du souverain ; on aimerait à penser que la tour maîtresse lui servit d'espace privatif lorsqu'il résida à Vernon, en particulier pendant les épisodes de la conquête de la Normandie, mais, si ce fut le cas, cette fonction n'a évidemment pas laissé de trace.

De l'autre côté du fleuve, la tour de Vernonnet venait apporter un contrepoint tout aussi remarquable. Contrairement à beaucoup d'ouvrages formant tête de pont, qui étaient en fait des tours-portes, cette tour était une véritable tour maîtresse contrôlant l'ouvrage mais isolée de lui ; jamais aucune tour maîtresse attribuée à Philippe Auguste n'avait jusqu'à présent été identifiée qui ait un tel plan carré cantonné de tourelles circulaires. Ceci montre pour le moins que le champ des possibles reste encore largement ouvert dans l'évaluation de l'architecture royale et que le paradigme de la tour maîtresse circulaire dut coexister avec d'autres formes, utilisées dans le contexte de la fortification urbaine, tout particulièrement.

Un tel plan ne peut apparaître comme une nouveauté à l'époque où il fut mis en œuvre ; bien des auteurs ont déjà tracé le cheminement du concept, avec ses jalons que furent Étampes, Houdan, Provins, Mez-le-Maréchal. En revanche, ce qu'on doit remarquer à propos de Vernonnet est la mise en œuvre systématique de tourelles flanquantes à archères multiples de type " philippien " dans une tour maîtresse. D'une certaine manière, l'architecte a combiné ici un plan déjà connu et utilisé, avec l'usage systématique de l'archère. À l'époque exactement où la tour de Vernonnet était construite, se construisait à une cinquantaine de kilomètres au nord, sur l'Andelle, une tour conçue exactement sur le même principe, à Douville-sur-l'Andelle, succédané ou concurrente, on ne sait ${ }^{57}$.

Et pourtant, la tour de Vernonnet fut, à n'en pas douter, une tour à vocation résidentielle : l'aménagement de la salle du 
premier étage, l'existence de deux tourelles plus spacieuses, dont une disposant de latrines, le prouvent et la présence du décor sculpté le confirme s'il le fallait. On peut en revanche s'interroger sur la raison d'un tel décor sculpté, inconnu dans la production royale contemporaine. Faut-il penser que la tour était supposée pouvoir accueillir le roi lui-même en certaines occasions? Ou doit-on penser qu'il s'agit ici tout simplement d'une fantaisie du maître d'ouvrage délégué, qu'il ait été le châtelain de Vernon ou un autre officier?

Enfin, pour terminer cette évocation de la place occupée par ces ouvrages vernonnais dans l'ensemble de la production royale, on ne manquera pas d'y souligner la coexistence de formes et de concepts hérités avec des usages architecturaux jusque-là peu utilisés dans l'architecture de la fortification. Ainsi en est-il, par exemple, du contraste entre la vis à voûte hélicoïdale de Vernonnet et la vis à noyau portant marches de la tour de Vernon ; ainsi en est-il également de la coexistence entre les voûtes en coupole sur couchis avec les voûtes sur croisées d'ogives. On se gardera d'y voir, comme le prétendaient autrefois les auteurs, le rattrapage chaotique d'un " retard " de l'architecture de la fortification par rapport à l'architecture civile ou religieuse ; au contraire, on peut y voir les tâtonnements qui allaient déboucher sur la mise au point d'un véritable cahier de spécifications types, propres à l'architecture de la fortification royale.

On en voit déjà les prémisses à Guainville, Vernon et Vernonnet, avec la pratique systématique des tours voûtées de coupoles exclusivement au niveau du deuxième étage, percées d'archères à ébrasement simple sous voûte plein cintre ou légèrement brisée. Ce caractère se manifeste également dans une fortification à peu près contemporaine développée à Gisors (tour du Diable, tour du Gouverneur) ${ }^{58}$.

En somme, les tours de Vernon et de Vernonnet constituent un jalon exceptionnel de l'architecture royale française à la charnière entre $\mathrm{XII}^{\mathrm{e}}$ et $\mathrm{XIII}^{\mathrm{e}}$ siècle ; on peut regretter que leur méconnaissance puisse conduire l'une d'entre elles à une poursuite inéluctable de la dégradation qui l'affecte depuis la Seconde Guerre mondiale, malgré les restaurations qui l'ont concernée.

\section{La mâ̂trise d'ouvre et les artistes}

L'architecture déployée à Vernon invite à se reposer la question de la maîtrise d'œuvre des chantiers royaux trop souvent dits " militaires ". Depuis une trentaine d'années, s'est répandue l'idée que Philippe Auguste organisa la maîtrise d'ouvrage et la maîtrise d'œuvre de ses châteaux et fortifications autour d'un ensemble d'ingénieurs qui auraient diffusé la normalisation, au point qu'on a employé le concept moderniste de " corps d'ingénieurs militaires de Philippe Auguste " 59 .

En fait, les documents administratifs publiés de longue date, consistant en devis de construction ou plutôt en baux à la tâche, permettent d'identifier un certain nombre de " maîtres " qui œuvrèrent sur des chantiers de fortification royaux, certains d'entre eux intervenant sur des sites éloignés les uns des autres ${ }^{60}$. Rien ne permet dans les documents de leur donner le titre d' " ingénieurs ", et moins encore celui de fonctionnaires royaux.
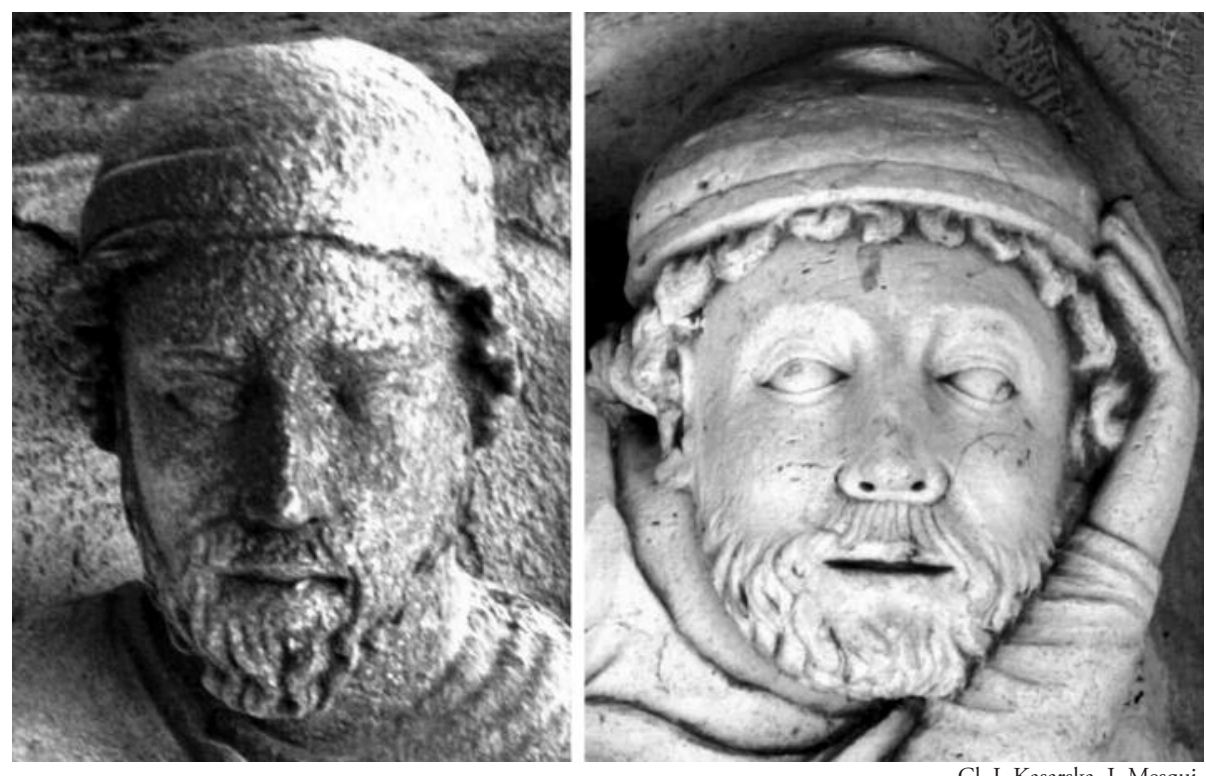

Cl. I. Kasarska, J. Mesqui.

Fig. 29 - Vernon, juxtaposition de la tête de l'allégorie de l'architecture de Laon et de la tête de l'homme courbé de Vernon.
En effet, ces pièces administratives permettent clairement d'identifier leur rôle : il s'agissait bel et bien d' " entrepreneurs" chargés de travaux à la tâche, on dirait aujourd'hui au marché forfaitaire. Chacun d'entre eux était rémunéré pour un ouvrage déterminé : une certaine longueur de murs ou de fossés, une ou plusieurs tours, une ou plusieurs portes, etc., suivant des devis établis par l'administration royale, ce qui est traduit par les textes : sicut rex divisit. Cette référence directe au roi comme donneur d'ordre ne doit pas ici tromper : il s'agit bien d'une formule destinée à montrer que l'ordre est passé au nom du roi directement, non pas en celui d'un officier local, mais on ne peut en tirer la conclusion que le roi lui-même établissait programmes et devis. D'ailleurs dans deux des descriptions sommaires de ces contrats à la tâche, c'est un certain maître Amaury qui est désigné comme ayant dressé le devis ; ce maître Amaury ne fut titulaire d'aucun des contrats conservés, confirmant qu'il faisait partie de l'échelon de la maîtrise d'ouvrage ${ }^{61}$.

Le rôle de ce maître Amaury se déduit du contenu même des marchés : il s'agissait de celui qui établissait le programme - plan de l'ouvrage, nombre de tours, largeur et profondeur des fossés, dimensions des ouvrages. Quant à la définition précise de 
ceux-ci, elle devait être laissée à chacun des maitres retenus. Comme de coutume au Moyen Âge, ceux-ci étaient des artisansentrepreneurs, le plus souvent des maîtres maçons (mais aussi, dans les comptes, maîtres terrassiers) ; comme de coutume également jusqu'à la Renaissance, ils pouvaient assurer une partie ou même la totalité de la maîtrise d'œuvre, assumant une partie de la mission de l'architecte.

Récemment, Yves Gallet a proposé d'identifier l'un de ces maîtres, Gautier de Meulan, avec le maître maçon homonyme qui intervint pour terminer les parties hautes de la nef de l'abbatiale du Bec-Hellouin avant $1223{ }^{62}$. Une telle identification permet d'évacuer définitivement la trop hypothétique spécialisation en " architecture militaire " des maîtres employés par Philippe Auguste ; les ouvrages de Vernon et de Vernonnet en apportent une preuve tangible, montrant que le ou les maîtres employés ici intervenaient couramment sur des bâtiments religieux ou civils. L'inté-gration entre le programme architectural et le programme sculpté - on pensera en particulier à l'engoulant de Vernonnet ne laisse aucun doute sur ce point : il ne s'agit pas seulement ici de sculptures réalisées indépendamment, puis incorporées dans les ouvrages, mais bien d'éléments pensés avec ces derniers.

On a déjà souligné la parenté entre la sculpture mise en œuvre à la cathédrale de Laon et celle de Vernon ; qu'il nous soit permis d'y ajouter un clin d'œil qui répond peut-être à ceux que nous adressaient les artistes eux-mêmes. La cathé- drale de Laon conserve une représentation de l'architecture sous des traits masculins, qui avait déjà été remarquée par Viollet-le-Duc ; Dany Sandron, puis Iliana Kasarska, ont proposé d'y voir l'architecte lui-même ${ }^{63}$. En juxtaposant la tête de ce personnage avec celle du personnage courbé de la tour maîtresse, il est amusant de constater des ressemblances manifestes, qu'il s'agisse de la représentation de la barbe, du bonnet recouvrant la tête, jusqu'aux cheveux bouclés qui débordent de ce bonnet. Coïncidence sans doute, si l'on en juge par les traits eux-mêmes, plus émaciés dans la sculpture de Laon, mais on aimerait à penser, en définitive, que c'est le maître maçon qui présida à la construction de la tour de Vernon qui se représenta s'inclinant devant le roi...

\section{ANNEXE \\ 1377 N.ST. COMPTE DE TRAVAUX FAITS AU CHÂTEAU DE VERNONNET (CHARPENTE, COUVERTURE, PLÂTRERIE)}

Source : B.n.F., ms.fr. 26015, $n^{\circ} 2386$. Analysé dans Nortier 2000, $n^{\circ} 1551$ (date proposée environ 1380). Le document n'est pas daté mais la référence au terme de Pâques 1377 échu permet de proposer cette année, d'autant que deux quittances pour couverture des tourelles et du pavillon et pour travaux sur les gouttières sont conservées pour les 14 et 16 avril de 1377 (B.n.F., ms.fr. 26013, $n^{\circ} 1900$ et 1905)

\section{Ou chastel de Vernonniel.}

Pour une tasche de charpenterie :

- C'est assavoir pour avoir fait et mis en chascun post de la salle dudit chastel ou costé devers l'eaue corbeaux de deux piez et demi de long et bons liens par dessouz qui portent iceulx corbeaux ;

- Pour avoir fait et mis une perne tout au long sur quoy se ferment petiz chevronneaux qui ont esté couverts d'essende, et a chascun chevron six piez de long ;

- Et afin que les eaues ne pourrisissent les mesriens, pour avoir mis semblable- ment ou pignon devers Vernon corbeaux et liens cxcc comme en droit la cheminée qui y est ñe a mil [?] ;

- Et pour avoir clos de liches depuis la salle jusques à la tour ou costé devers l'eaue ;

- Et pour avoir mis une poutre de XXII piez de long ou comble de la tour, laquelle estoit arse par feu d'aventure ;

- Et pour avoir fait deux entretoises qui se ferment entre deux tyrans qui portent les solleaux des garites, pour y mettre IIII soleaux et troiz coulombes qui semblablement on esté arses ;

- Pour avoir abatu la closture de la vuys et avoir estayé le comble dessus dit jusques à ce que ladite besongne fut parfaite ;

- Et pour avoir emploié quarteron d'aes ou planchié d'un des gariteis d'icelle tour ;

- Et pour avoir fait et assis une émeneure en la cheminée du pignon de la haulte chambre, et pour avoir clos la vuys de la salle au rez des greniers, et esligier une huisserie et faire un huis tout neuf ;

- Et pour avoir mis et emploié demi quarteron d'aes sur le planchié des garites où mestier estoit.
Baillé en tasche à rabès accoustumé à Pierre Cugeron charpentier pour le pris de L 1.t, et a trouvé charroy, seage et toutes autres choses à ce nécessaires excepté que le roy messire lui a trouvé bois en estant, tant eullement. Et à lui demouré par ledit pris. Pour ce L 1.t.

Pour une tasche de couverture d'essende :

- C'est assavoir pour avoir fait et emploié XXIIIIm d'essende et un millier de late sur les couvertures des quatre tours et du paveillon dudit chastel, et oultre ce que avoit esté appointé au terme de Pasques LXXVII derrenier passé. Lesquelles tours et paveillon avoient esté descouvers pour cause du gariteys qui y a esté fait.

Baillé en tasche à abrès à Guillaume Quathelier et a trouvé charroy, seage, clou à asseoir ladite essende et late ainsi comme dit est, excepté bois en estant.. C'est assavoir chascun millier d'essende pour le pris de XL s.t. et le dit millier de late par le pris de IIII l.t.. Et pour ce pour tout LII l.t. 
- À Guillaume de Lulli, fèvre, pour avoir fait une chaenne de quatre piez de long et un estrieu pour retyrer la planquette dudit chastel, et pour une serreure et la caenne de pié et demi de long pour fermer à ladite serrure, pour ce XL s.t.

Pour une tasche de plastre :

- C’est assavoir pour avoir refait tout de neuf le planchié de la grosse tour lequel avoit esté rompu tant pour cause d'une poutre qui avoi esté mise en icelle tour, comme pour cause du gariteiz d'icelle qui a esté fait nouvellement ;

- Pour avoir refait les aumures d'icelle tour afin que l'on y puist mettre des garnisons ;

Je remercie vivement Pierre-Yves Le Pogam, conservateur en chef au musée du Louvre, d'avoir bien voulu me faire bénéficier du dépouillement exhaustif qu'il a effectué des quittances et pièces diverses sous le règne de Charles VII, conservées à la Bibliothèque nationale de France dans le cadre de sa thèse de l'École nationale des chartes.

\section{Baboux 1995}

J. Baboux, "À la découverte de la richesse du patrimoine vernonnais : Vernon et la frontière franco-normande au Moyen Âge, le château, la Tour des Archives et les remparts ", Les Cahiers Vernonnais, $\mathrm{n}^{\circ}$ spécial patrimoine, 1995.

\section{Baboux 1999}

J. Baboux, "Un tableau de Vernon de 1843 ", Les Cahiers Vernonnais, n ${ }^{\circ} 21$, 1999, p. 41-43.

\section{Baboux 2001}

J. Baboux, "Le château des Tourelles à Vernon : destin millénaire d'un châtelet philippien ", Construire, reconstruire, aménager le château en Normandie, Congrès des sociétés historiques et archéologiques de Normandie, t. 9, Caen, 2004, p. 233-246 (Actes du 38 congrès organisé par la fédération des sociétés historiques et archéologiques de Normandie, 2003).
- Pour avoir refait le planchié de la tourelle où gist le chastelain ;

- Et pour avoir clos de plastre une maison qui a esté faite nœuve sur la porte de Vernonniel, et fait le planchié d'icelle

- Pour avoir fait et haulchié de pierre le muret que est au costé de la porte devers la salle jusques à une poutre qui a esté faite nœuve qui soustient ladite maison afin que l'en ne puisse passer et entrer en ladite porte.

Cette tasche baillée à rabès à Guillaume Arragon et Jehan le Brioiz par le pris de XXIIII 1.t. et ont trouvé pierre, plastre, mortier et toutes autres choses à ce

\section{BIBLIOGRAPHIE}

\section{Baldwin 1991}

J. Baldwin, Philippe Auguste et son gouvernement, Paris, 1991.

\section{Brugerolles-Guillet 2001}

E. Brugerolles, D. Guillet Le dessin en France au XVII siècle dans les collections de l'École des beaux-arts, Paris, 2001.

\section{Bauduin 2006}

P. Bauduin, La Première Normandie ( $X^{e}-X I^{e}$ siècles), $2^{\mathrm{e}}$ éd, Caen, 2006.

\section{Cartulaire Normand}

L. Delisle, " Cartulaire normand de Philippe Auguste, Louis VIII, saint Louis et Philippe le Hardi ", Mémoires de la Société des Antiquaires de Normandie, t. 16 (2e série, t. 6), 1852.

\section{Cartulaire Saint-Père}

B. Guérard, Cartulaire de l'abbaye de SaintPère de Chartres, Paris, 1840.

\section{Castreau 2000}

J.-M. Castreau, " Une vue inédite de Vernon au XVIII ${ }^{\mathrm{e}}$ siècle ", Les Cahiers Vernonnais, n 31, 2009, p. 45-56.

\section{Castreau 2010}

J.-M. Castreau, "Le baptême d'une tour ", Les Cahiers Vernonnais, ${ }^{\circ} 32,2010$, p. 6268. nécessaires excepté que le Roy messire a trouvé boiz en estant pour escharfauder seullement. Rabaissé par Guillaume ( ?) et Jehan Mesnage et mise à XIX 1. VIII s.t. Pour ce XIX 1. VIII s.t.

À Guillaume de Lulli fèvre dessus dit pour avoir fait la penthure d'un huis pour les greniers de la salle haulte et y avoir ait une serreure à clef et un tyreur par marché à lui fait, pour ce XXIIII s.t.

S. CXIIII 1. XII s. $\mathrm{M}^{\circ}$ XVc XXVII 1. XV s. VII d.t. "

\section{Châtelain 1981}

A. Châtelain, " La nouvelle architecture militaire du XIII ${ }^{\mathrm{e}}$ siècle en Île-de-France ", dans Liber Castellorum, Zutphen, 1981, p. 66-75.

\section{Chronique Robert de Torigny}

L. Delisle, Chronique de Robert de Torigni, Rouen, 1872, 2 t.

\section{Corvisier 2004}

Chr. Corvisier, " Les châteaux de Richard Cœur de Lion, l'œuvre de pierre comme démonstration de force ", dans Actes $d u$ colloque du 800 anniversaire de la mort de Richard Cour de Lion. Caen, avril 1999, Caen, 2004, p. 198-217.

\section{Corvisier 2006}

Chr. Corvisier, "La fortification castrale des Plantagenêt en Normandie ", dans Actes de la Table Ronde "Les fortifications et châteaux Plantagenêt" au sein du colloque "Cinquante années d'études médiévales. À la confluence de nos disciplines " tenu à Poitiers du 1 au 4 septembre 2003, Bruxelles, 2006, p. 111-148.

\section{Dechezleprêtre 1998}

Th. Dechezleprêtre et al., La fortification gauloise de Vernon : recherches récentes sur un oppidum des Veliocasses, Vernon, musée Alphonse-Georges Poulain, 1998. 


\section{Delisle 1851}

L. Delisle, Études sur la condition agricole et l'état de l'agriculture en Normandie au Moyen Âge, Évreux, 1851.

\section{Dion 1959}

R. Dion, Histoire de la vigne et du vin des origines au XIX siècle, Paris, 1959, p. 218219.

\section{Douët d'Arcq 1863}

L. Douët d'Arcq, Choix de pièces inédites relatives au règne de Charles VI, Paris, t. I, 1863.

\section{Erlande-Brandenburg 1980}

A. Erlande-Brandenburg, "L'architecture militaire au temps de Philippe Auguste : une nouvelle conception de la défense " ", dans La France de Philippe Auguste. Le temps des mutations, Actes du colloque international organisé par le CNRS (1980), Paris, 1982, p. 595-603.

\section{Erlande-Brandenburg 1983}

A. Erlande-Brandenburg, "L'organisation du conseil d'architecture militaire et du corps des spécialistes sous Philippe Auguste " ", Artistes, artisans et production artistique au Moyen Âge, Actes du colloque international organisé par le CNRS (1983), Paris, 1990, p. 214-219.

\section{Gallet 1997}

Y. Gallet, "Gautier de Meulan, un «architecte-ingénieur» méconnu du début du XIII siècle ", Bull. mon., 1997, p. 135138.

\section{Goudeau 1990}

A. Goudeau, " La minoterie de Vernonnet ", Les Cahiers Vernonnais, ${ }^{\circ} 13$, 1990, p. 5-18.

\section{Goudeau 2002}

A. Goudeau, Trois siècles d'histoires vernonnaises, Vernon, 2002.

\section{Goudeau 2010}

A. Goudeau, "Un chancelier du duc d'Orléans, Jean-Baptiste Lemoyne de Bellisle (1716-1791), seigneur de Vernonnet et de Lavilletertre ", Les Cahiers Vernonnais, $n^{\circ} 32,2010$, p. 51-61.

\section{Goudeau 2011}

A. Goudeau, "Vernon pendant la Révolution ", Les Cahiers Vernonnais, ${ }^{\circ} 33$, 2011.

\section{Kasarska 2008}

I. Kasarska, La sculpture de la façade de la cathédrale de Laon : eschatologie et humanisme, Paris, 2008.

\section{Lot-Fawtier 1932}

F. Lot, R. Fawtier Le premier budget de la monarchie française, Paris, 2 fasc., 1932 (Bibliothèque de l'École des Hautes Études, fasc. 259).

\section{Mesqui 1991-1993}

J. Mesqui, Châteaux et enceintes de la France médiévale, Paris, 2 t., 1991-1993.

\section{Mesqui 2012}

J. Mesqui, "L'implantation de l'HôtelDieu de Vernon en 1256. Hypothèses sur le site du premier château et le développement de la ville du XI ${ }^{\mathrm{e}}$ au XIII ${ }^{\mathrm{e}}$ siècle ",à paraître dans Les Cahiers vernonnais, 2012.

\section{Meyer 1874-1876}

Éd. Meyer, Histoire de la ville de Vernon et de sa châtellenie, 2 t., Les Andelys, 18741876.

\section{Mirot 1921}

L. Mirot, "Paiements et quittances de travaux exécutés sous le règne de Charles VI ", Bibliothèque de l'École des chartes, t. LXXXI, 1920.

\section{Nortier 2000}

$\mathrm{M}$. Nortier, Documents normands du règne de Charles V, Paris, 2000.

\section{Pitte 1990}

D. Pitte, Le vieux château de Vernon, Vernon, 1990 (Vernon, musée AlphonseGeorges Poulain).

\section{Pitte 2006}

D. Pitte, «Apports récents de l'archéologie à la connaissance des villes de HauteNormandie au Moyen Âge (1975-200) ", dans P. Bouet, Fr. Neveu (éd.), Les villes normandes au Moyen Âge, Caen, 2006, p. 141-157.

\section{Pitte-Gauthiez 1987}

D. Pitte, B. Gauthiez, Le château de Philippe Auguste, Rouen, 1987.

\section{Pouëssel 2005}

J. Pouëssel, "Vernon et sa vicomté ", Les Cahiers Vernonnais, $\mathrm{n}^{\circ} 27,2005$, p. 19-60.

\section{Poulain 1957}

A.-G. Poulain, Les séjours du roi Saint Louis en Normandie et particulièrement à Vernonsur-Seine, Rouen, 2e éd., 1957.

\section{Poulain 1982}

A.-G. Poulain, $A$ travers le vieux Vernon, Évreux, $3^{e}$ éd., 1982 (1éd., 1937 ; 2e éd., 1953).

\section{Power 2007}

D. Power, The Norman Frontier in the Twelfth and Early Thirteenth Centuries, Cambridge, 2004, 2e éd., 2007.

\section{Registres Philippe Auguste}

J. W. Baldwin, Les Registres de Philippe Auguste, Paris, 1992 (Documents inédits sur l'histoire de France, Documents financiers et administratifs, vol. 7).

\section{Sandron 1999}

D. Sandron, « La cathédrale et l'architecte : à propos de la façade ouest de la cathédrale de Laon ", Pierre, lumière, couleur, études d'histoire de l'art du Moyen Âge en l'honneur d'Anne Prache; textes réunis par Fabienne Joubert et Dany Sandron, Paris, 1999, p. 133-150.

\section{Spalikowski 1918}

E. Spalikowski, Une sculpture romane de la tour des Archives à Vernon (Eure), Paris, 1918 (ce fascicule a été édité chez Auguste Picard, sans doute à compte d'auteur et à très faible diffusion. On le trouve en particulier à la médiathèque de Vernon, fonds ancien). 


\section{NOTES}

Je tiens à remercier ici très vivement Jean Baboux, éminent membre du Cercle d'études Vernonnais, qui m’a fait bénéficier de son érudition et m'a apporté un précieux concours pour l'accès aux documents historiques concernant Vernon. Je remercie également Jean Castreau de m'avoir ouvert sa vaste documentation iconographique.

1. Il n'existe strictement aucune étude de fond de la tour des Archives qui n'a fait l'objet que de mentions dans les ouvrages consacrés à l'architecture " militaire ». En revanche, le fort des Tourelles a bénéficié récemment de l'attention de Jean Baboux qui y a consacré un article historique et en a mis en exergue l'intérêt archéologique : Baboux 2001. Voir également la brève notice du même auteur sur les deux édifices : Baboux 1995.

2. Voir Pitte 2006, en particulier p. 144-145. Bauduin 2006, p. 232, reprend l'opinion ancienne suivant laquelle une agglomération gallo-romaine exista à Vernon mais en remarquant quaucun indice archéologique n'en a été exhumé.

3. Dechezleprêtre 1998. Sur la chapelle Saint-Michel, voir Meyer 1874-1876.

4. Bauduin 2006, p. 232-242.

5. Le premier érudit à avoir mis en valeur ce vignoble est Delisle 1851. Voir depuis par exemple Dion 1959, p. 218-219, etc.

6. Cartulaire Saint-Père, t. I, p. 178-179. Chronique Robert de Torigni, t. I, p. 165.

7. Chronique Robert de Torigni, t. I, p. 233, 268.

8. Ibid., p. 277, 285. Firmissimum castrum : Chronique de Lambert de Waterloo, dans Recueil des Historiens de France, XIII, p. 509.

9. Ces événements sont suffisamment connus pour qu'on se contente de donner ici une des références les plus récentes : Power 2007, en particulier p. 420-421.

10. Philippe Auguste y fut tous les ans de 1196 à la fin de la conquête de la Normandie ; par la suite, ses séjours semblent s'être espacés puisqu'on n'établit sa présence qu'en 1205, 1207, 1215 et 1219 (voir Cartulaire Normand, passim ; Catalogue Philippe Auguste, itinéraire, p. CIII et suiv.). Pour Saint Louis, qui y passa en 1227, 1231-1232, 1239, 1256-1257, 1259, 1261 et 1269, voir Cartulaire Normand, passim. On consultera avec fruit l'ouvrage, un peu dépassé, d'Alphonse-Georges Poulain : Poulain 1957.

11. Sur l'histoire générale de Vernon, voir Meyer 1874-1876. Pour les périodes plus récentes, on la complètera en consultant les excellents Cahiers vernonnais publiés par le Cercle d'études vernonnais ; voir aussi Goudeau 2002.

\section{Voir Mesqui 2012 (à paraître).}

13. Bastion dit de l'Éperon à l'ouest, double bastion de la tour du Vieux-René au sud-ouest, visibles dans les plans anciens de la ville. Voir Meyer 1874-1876, t. I, p. 374-402 sur l'histoire des fortifications de la ville, en particulier à partir du XVI siècle.
14. « Ceste vile est une moult bonne place et forte, car il y a ung petit chastel moult fort nommé Vernonnet, et ung autre très fort dedens la ville dont estoit capitaine le filz du conte d'Ormont d'Irlande qui avoit en sa compaignie xii vingtz combatans, lesquels composèrent à rendre ladicte place lendemain ou cas qu'ilz ne seroient les plus fors dedens le samedi ensuivant heure de prime. Mais ilz ne furent point secouruz pour ce que les autres Englois n'osoient eulx partir de Rouen. " (Les Cronicques de Normendie par Guillaume le Talleur, 1487, éd. A. Hellot, Rouen, 1881, p. 112-113).

15. Meyer 1874-1876, t. II, p. 307 : « une maison était placée, en 1426, "jouxte la porte neuve du pont" ".

16. Meyer 1874-1876, t. I, p. 398, en donne les dimensions (26 pieds de longueur, 22 de largeur et 28 à 30 de hauteur). Voir le lavis de Nicolas de Plattemontagne, daté de 1654, publié dans Brugerolles-Guillet 2001, qui donne une excellente vue prise du sud-ouest. Une vue de Samuel Hieronymus Grimm prise en 1767 montre que la tour-porte avait disparu (H. Plaideux, "Samuel Hieronymus Grimm (1733-1794), ses œuvres en Normandie et l'iconographie authentique de l'abbaye de Cherbourg ", Actes du 45 e Congrès des Sociétés historiques et archéologiques de Normandie, à paraître).

17. Pitte 1990. Voir aussi Meyer 1874-1876, t. I, p. 381-384 et p. 390-397. Concernant les plans anciens, les plus importants sont :

- le plan de 1593 conservé à la B.n.F. : "Plan geometrial de la ville de Vernon sur Seyne avec l'elevation des bastimentz publiques » : B.n.F., Est., Coll. Gaignières, n 5191 (accessible en ligne sur Gallica).

- le plan de 1779 conservé au musée de Vernon.

18. Le plan de 1593 faisait aussi apparaître une tourelle circulaire entre la Grosse tour et la tour d'angle sud-est mais il ne pouvait s'agir que d'un élément adventice qui a disparu depuis.

19. Pitte 1990, p. 24, photographie $\mathrm{n}^{\circ} 12$.

20. Pitte 1990, p. 25-28 et planche 1.

21. Datation proposée par Pitte 1990, p. 13 ; Mesqui 1991-1993, I, p. 260-262.

22. Castreau 2010 : la dénomination a été donnée par le père du propriétaire actuel du jardin et de la maison attenants. En 1911, elle était appelée " Tour ovale " dans une délibération de la ville (Arch. mun.Vernon, 1D38, 31 mars 1911).

23. Très curieusement, cette tour est décrite comme " ayant des angles " par les visiteurs du château en 1719 (Meyer 1874-1876, t. I, p. 390-391, reproduit dans Pitte 1990, p. 14 n.8). Ceci a conduit E. Meyer à représenter une tour à la circonférence formée d'une succession d'angles droits dans sa mise en trois dimensions du plan de 1593 (Meyer 1874-1876, II, p. 30). Cette vue cavalière faussement ancienne a été inspirée, pour la restitution des élévations, de la gravure de Claude Chastillon; elle n'a aucun caractère authentique (reproduction dans Pitte 2010, p. 22, photographie 11, qui s'interroge sur son origine...).

24. Outre notre plan, dressé à l'aide de nos propres relevés en 2010, voir le plan de 1907 dressé par l'architecte Gouchot pour le propriétaire du jardin et maison attenants, maître Grimpard (Castreau 2010, p. 68) ; voir aussi le plan dressé par l'architecte en chef des Monuments historiques Ruprich-Robert, en 1909 (Médiathèque de l'Architecture et du Patrimoine, 1996/025/361)

\section{Voir Mesqui 2012.}

26. Grosse tour : voir par exemple quittance du 4 juillet 1405 pour couverture de l'échauguette et la lucarne de la "grosse tour " (B.n.F., ms. fr. 26034, $\mathrm{n}^{\circ}$ 3738). Tour de la Cigogne : voir quittance du 2 septembre 1403 la mentionnant (B.n.F., ms. fr. $26033, n^{\circ} 3518$ ) : " pour avoir esquis jusques au vif fons XX toises d'autres tallus qui sont l'endroict de la tour nommée la Segongne, autour de la barrière dudit chastel ». Voir aussi la quittance de 1415 en note 28

27. Nombreux détails sur les événements ayant marqué la tour aux XIX'-XXe siècles dans Baboux 1995, p. 21-35. L'auteur publie l'élévation de l'architecte et restaurateur Bourguignon en 1838 (les archives de la ville contiennent également une excellente coupe du même architecte).

28. B.n.F., ms. fr. 26040, nº 4937 : « Premièrement pour avoir osté tous les gravoiz de la tour nommée la Sigongne derrainement faite devers l'ostel Robert Belle, et avoir osté hors de tous les estages et porté hors de ladite tour et dudit chastel; et pour avoir vuidié l'alée de haut de devers la rue Potart et avoir mis les caillous encontre la visz derrainement faite et encontre les murs emprès icelle visz et pour avoir mis l'engin de ladite tour à couvert, LII s.p. ».

29. B.n.F., ms. fr. $26034, n^{\circ} 3738$; Quittance de Vincent le Roy, estainier de Vernon : «- pour avoir plommé et couvert de plon l'eschauguette de la grosse tour dudit chastel et plommé tout autour icelle eschauguette tant en posts cille en coulombes avec l'espy d'icelle où la bande siet avec le basin dudit espy (...) ; pour avoir plommé les quatre lucarnes de ladite tour, les espis d'icelle avec les justes et bacins, et aoivr plommé en front de devant et ès posts desdites lucarnes (...)». (1405, 4 juillet)

30. Les sculptures ont été révélées pour la première fois par l'écrivain-poète atypique que fut Edmond Spalikowski, fils du docteur homonyme, qui écrivit entre les deux guerres : voir Spalikowski 1918. Cependant, l'auteur voyait dans cette sculpture un ensemble du XII siècle, se fiant à l'attribution de la tour à Henri Ier vers 1123, courante à l'époque (et encore de nos jours).

31. Je remercie très vivement Éliane Vergnolle, Yves Gallet, Philippe Plagnieux et Iliana Kasarska d'avoir bien voulu me faire profiter de leur expertise et de m'avoir fait part de leur sentiment sur ces sculptures. Sur la sculpture des années 1200, voir Kasarska 2008, p. 203 et suiv. ; on peut trouver de fortes analogies entre la sculpture de l'homme barbu de Vernon et, par 
exemple, l'homme pris dans les griffes de la gargouille de la cathédrale de Laon, que Iliana Kasarska attribue à une " manière B " dans la sculpture de cette cathédrale (Kasarska 2008, Corpus, p. 596, à partir de M. Camille, "Gargouilles : fantômes du patrimoine et avenirs des monuments médiévaux ", $L e$ Musée de sculpture comparée. Naissance de l'art moderne, 1999, p. 91).

32. Lot-Fawtier 1932. Le compte de 1202-1203 ne mentionne des travaux à Vernon que de façon assez annexe (p. CLXVI : fossés et bretêches - " pro fossatis Vernon et breteschiae cooperire»; p. CLXX: curage de latrines - " pro cameris privatis apud Vernonem curandis "; p. CCIX : couverture de la barrière - " pro garrolio Vernonis cooperiendo"; couverture des salles, construction d'un appentis et réfection d'un mur tombé - " pro aulis Vernonis cooperiendis et pro uno apenticio faciendo et pro muro caso reficiendo").

33. Voir note $\mathrm{n}^{\circ} 10$.

34. Premiers exemples : B.n.F. : ms. fr. 20012, $\mathrm{n}^{\circ} 1525$ "tour de Vernonniel " (1372); 26011, $\mathrm{n}^{\circ} 1342$ : «chastel de Vernonniel » (1373). Nombreux autres exemples dans les quittances et pièces diverses.

35. Lot-Fawtier 1932, p. CXLVII : "Magister Hugo, pro custodia turris, XXX l. "; p. CCIX "Magister Hugo, pro custodia turris de ponte, XX l.». On peut avec certitude identifier cette tour du pont au fort des Tourelles : en effet, les deux inventaires d'armement faits durant le règne de Philippe Auguste (Cartulaire normand, $\left.\mathrm{n}^{\circ} 214,215\right)$ mentionnent l'un : « in capite pontis IIII balistas ad estrif et XXIX lorcias et IIII loriculas et XXXII galeas duplices", l'autre : « in turre pontis Vernonis XIIII lorice, II habergeons, V coiffe ferree, XIIII helmi ». Il s'agit bien dans les deux cas de la tour située à la tête du pont, c'est-à-dire la tour de Vernonnet.

\section{Goudeau 2010, p. 52}

37. L'histoire moderne des Tourelles de Vernon, à partir du XVII siècle, a été brillamment synthétisée par Baboux 2001. On n'y reviendra donc pas ici. Voir, pour plus de détails, les différentes études historiques d'André Goudeau, en particulier Goudeau 1990 qui retrace l'histoire de la minoterie ; Goudeau 2002, Goudeau 2011, passim, qui donnent diverses anecdotes relatives aux différents industriels qui se succédèrent à partir de la Révolution sur le site des Tourelles. Voir aussi Poulain 1982, p. 48-53.

38. Voir le plan conservé aux Arch. nat., F14 1019613-04, publié ici en figure 4. Un autre plan contemporain, dressé de la même main, est conservé au musée de Vernon : il montre un projet de restauration des arches de rive droite par des travées de bois sur piles de pierre, projet qui fut réalisé.

39. Voir la reproduction photographique d'un tableau de 1843 représentant le bâtiment Planter au-dessus de l'ancienne enceinte depuis le sud, dans Baboux 1999 ; autre reproduction de la même dans Goudeau 2011, pl.h.t. face à la page 16. Autre vue très intéressante, prise depuis le sud-ouest à l'époque révolutionnaire, en p. 94 de la même publication.

40. Voir l'histoire de la tannerie Ogerau dans Goudeau 2002, p. 157-171.
41. B.n.F., ms. fr. 26073, nº 5133 : « C’est assavoir au bout du pont de Vernon au bollevert de la tour de Vernonniel, mis et assis au pont-levis dudit chastel six aez de la laise du pont, par ce que ceulx qui y estoient estoient tous démis et n'y povoit l'on mès passer que à grant péril et dangier» (5 janvier 1445 n.st.).

42. B.n.F., ms. fr. $26066, n^{\circ} 3908$ : travaux faits sur " une garde faite sur le pont dormant entre la herse et le pont-levis "; nouvelle porte faite dans cette " garde" (11 décembre 1439).

43. Annexe 1 : «pour avoir clos de liches depuis la salle jusques à la tour ou costé devers l'eaue " ( "liches " pour lices, au sens de barrières, palissades).

44. Voir par exemple en 1589, le bail d'une arche et pêcherie sous le pont de Vernon, nommée « l'Arche du Chastel ", avec les fossés de la tour de Vernonnet (Arch. dép Eure, E 1389, fol. 105). Voir l'acte d'échange du 18 décembre 1759 : « un petit château appelé le château de Vernonnet dont il ne reste qu'une tour quarrée flanquée de quatre petites tourelles rondes et d'une partie de mur de clôture, le tout en reuine, autour duquel château il y a des vestiges de fossés presque comblés, isles et pescheries (...) ", cité par Goudeau 2010, p. 52.

45. " RESTA $[U R] A T U[M]$ A $[N N O$ DOMINI $M D C] C L X V$ ». C'est de façon erronée que Poulain 1982 donne la lecture "Restauravit anno domini $1763 »$.

46. La gravure de Chastillon, comme celle de Duviert publiée ici, qui datent toutes deux du début du $\mathrm{XVII}^{\mathrm{e}}$ siècle, représentent la tour avec un parapet crénelé, sans toit ni sur le pavillon central ni sur les tourelles.

47. Les mentions de réfections du pont-dormant, du pont-levis, et de la planchette de la tour ou du château sont extrêmement fréquentes dans les quittances de travaux de la fin du XIV et du XVe siècle mais il est pratiquement impossible de déterminer si elles concernent l'accès direct à la tour ou l'accès à l'enceinte sud. Voir par exemple B.n.F., ms. fr. 16011, $\mathrm{n}^{\circ} 1422$; " pour avoir ralongné les qeennez [chaînes] du pont de la tour de Vernonniel " (1373) ; 26031, $\mathrm{n}^{\circ} 3269$ : " pour avoir fait et mis une solle séant sur la machonnerie de VIII piez de long ou environ et de I espine de reffais et se ferme au post qui porte la planchette et d'autre bout à la machonnerie de dessus ladite sole "; " et avoir clos le pont de bonnez et par costé devers la planchete d'une toise de hault ou environ et avoir renformé ledit pont-levis »; « et pour avoir renformé le pont dormant " (1401) ; 26066, $\mathrm{n}^{\circ} 3908$ : " pour avoir fait IIII bougons de fer lesquelz souspendent une garde de nouvel faite sur le pont dormant entre la herse et le pont-levis "; " pour deux gons et deux vertevelles, ung touroule, une clicquette et ung tireur en un huis nouvellement fait en ladicte garde "; "pour une clef pour la serrure de la planchette de la tour " (1439), etc.

48. Annexe $1:$ « pour avoir assis une emeneure en la cheminée du pignon de la haulte chambre » (1377 n.st.).

49. Annexe 1 : " pour avoir refait le planchié de la tourelle où gist le chastelain " (1377 n.st.). B.n.F., ms. fr. 26031, n 3269 : « pour avoir rechangé soleaux de six pieds de long ou environ soubs la chapelle de la tour, chascun solel d'un pied de refet ou environ. » (1401).

50. B.n.F., ms. fr. 26011, $\mathrm{n}^{\circ} 1421$ : «pour avoir couvert la salle de la tour de Vernonniel» (1373).

51. Annexe $1:$ « Lesquelles tours et paveillon avoient esté descouvers pour cause du gariteys qui y a esté fait ".

52. Poulain 1982, p. 50 (description de la tour en 1933).

53. Les plans anciens montrent que Vernon reçut dans la seconde moitié du XVI siècle une fortification de transition ; mais il est probable aussi que la tour du Vieux-René, disparue aujourd'hui, ne fut édifiée qu'à la fin du XVe siècle. On conserve par ailleurs des vues fiables de l'ancienne porte de l'Eau, probablement attribuable au XVI ${ }^{\text {e }}$ siècle également. On peut espérer qu'une étude y soit consacrée un jour prochain.

54. La datation de Bourges est suffisamment documentée depuis longtemps pour que l'on n'y revienne pas; en revanche, concernant la tour du Palais de Paris, nous épousons totalement la thèse de Jean Guerout suivant laquelle c'est cette tour, et non celle du Louvre, qui est mentionnée dans le compte de 1202-1203, alors que celle du Louvre n'est entamée qu'un an plus tard (Guerout, p. 138-142). Les similitudes entre la tour du Palais et les autres tours de Philippe Auguste incitent par ailleurs à s'interroger sur l'attribution classique à Louis XVI, reprise par Guerout p. 125-126.

55. Il n'entre pas dans l'objet du présent article de traiter de l'ensemble de la fortification de Philippe Auguste. En attendant une étude renouvelée de celleci, on consultera avec fruit Châtelain 1991.

56. Paris : Mesures calculées à partir du plan cadastral du XVIII'siècle (B.n.F., Est., Coll. Destailleur, t. 6, $\mathrm{n}^{\circ}$ 1218) et le plan de Delagrive de 1754. Bourges : Mesures données par G. Thaumas de la Thaumassière, Histoire du Berry, éd. Chevalier de Saint-Amand, Bourges, 1865, t. I, p. 208-209.

57. Château mentionné et rapidement décrit par Corvisier 2004, Corvisier 2006.

58. Voir J. Mesqui, Les seigneurs d'Irry, Bréval et Anet aux XI et XII siècles, Caen, Société des antiquaires de Normandie, 2011, p. 171-209.

59. A. Erlande-Brandenburg a formalisé cette idée en avançant l'existence d'un " conseil d'architecture militaire " et d'un « corps de spécialistes », souvent reprise ensuite sous l'appellation de " corps d'ingénieurs " par référence aux corps d'ingénieurs-fonctionnaires spécialisés qui naquirent aux XVII et XVIII siècles dans la France absolutiste. Erlande-Brandenburg 1980 ; Erlande-Brandenburg 1983. Voir aussi Baldwin 1991, p. 378-387, qui reprend l'idée.

60. La publication la plus récente et complète est celle de John Baldwin dans Registres Philippe Auguste, p. $245-250$.

61. Registres Philippe-Auguste, p. 247, nos 14 et 15.

62 Gallet 1997.

63. Sandron 1999. Kasarska 2008, p. 104-105. 